\title{
In Vivo Bacterial Morphogenetic Protein Interactions
}

\author{
René van der Ploeg and Tanneke den Blaauwen \\ University of Amsterdam, Swammerdam Institute for Life Sciences, \\ The Netherland
}

\section{Introduction}

\subsection{Techniques to study protein-protein interactions in cell division}

This chapter will discuss none-invasive techniques that are widely used to study proteinprotein interactions. As an example, their application in exploring interactions between proteins involved in bacterial cell division will be evaluated. First, bacterial morphology and cell division of the rod-shaped bacterium Escherichia coli will be introduced. Next, three bacterial two-hybrid methods and three Förster resonance energy transfer detection methods that are frequently applied to detect interactions between proteins will be described and discussed in detail. The chapter concludes with a discussion about the application and results of the techniques when studying proteins involved in cell division.

\section{Cell morphology}

\subsection{The bacterial cell wall}

Bacteria have different shapes with the most common being spheres and rods. The morphology is determined by the cell wall that surrounds the cytoplasmic membrane of a bacterium. This cell wall is one large closed molecule called sacculus that keeps everything together. Breaches in the structure can be fatal causing rupture enforced by the high internal (turgor) osmotic pressure. Preserving the strength of the wall during growth and division is therefore vital. The exact architecture of the peptidoglycan network is under debate but its composition is identified (Dmitriev et al., 2005; Gan et al., 2008; Hayhurst et al., 2008; Vollmer \& Seligman 2010a).

The entire structure is built from linear polymers cross-linked by short (stem) peptides. Each polymer is a repetition of a $\beta$-1,4-linked $\mathrm{N}$-acetylglucosamine (GlcNAc) and $\mathrm{N}$ acetylmuramic acid (MurNAc) unit, ending with a head group. The head group is different from the GlcNAc, MurNAc disaccharide unit in that the MurNAc subunit has a 1,6 intramolecular ether-linkage from C-1 to C-6. The bridging stem peptides are synthesized as pentapeptides with an amino acid sequence of L-Ala, D-Glu, mesoA2pm, D-Ala, D-Ala. Although, the sacculus is made of repetitions of disaccharide pentapeptides, small variations in the fine structure exist. The network is not stiff but has a remarkable flexibility and can shrink and expand with about 3 times its size (Koch \& Woeste 1992;). This elastic 
property is functional important in a changing osmotic environment that evokes spontaneous but drastic increases and decreases in the turgor pressures. For growth and division the cell wall is continuously expanded and renewed. Proteins located in the cytoplasm, periplasm and membranes work together to make this possible. Penicillinbinding proteins (PBPs) are responsible for the synthesis and modification of the network. For the rod-shaped bacterium E. coli twelve different PBPs have been identified. Only a few produce clear phenotypes, most of them are not essential (Denome et al., 1999) indicating redundancy. For a broad overview of the penicillin-binding proteins from E. coli and several other Gram-negative and positive bacteria the reader is referred to (Sauvage et al., 2008). More information on the cell wall structure can be found in the reviews (Vollmer et al., 2008; Vollmer \& Bertsche, 2008; Vollmer \& Seligman, 2010).

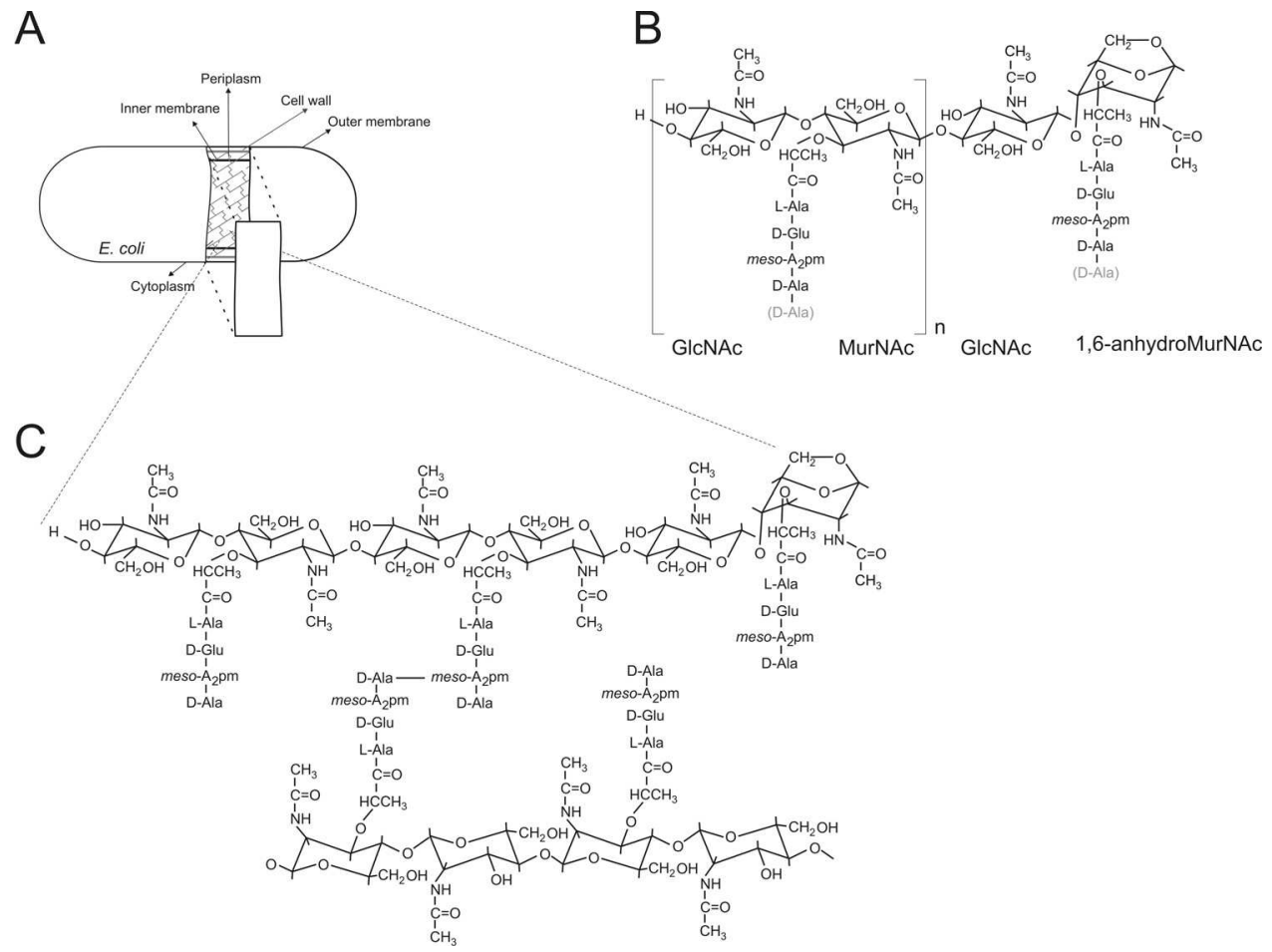

Fig. 1. A simplified presentation of the E. coli cell wall structure. A) The cell wall found in the periplasm of $E$. coli is build from cross-linked glycan strands. B) A glycan strand and its cross-linking in the network $(\mathrm{C})$. The last D-Ala residue is enzymatically removed in the mature macromolecule and is therefore depicted in grey $(\mathrm{B})$.

\section{Cell division of Escherichia coli}

\subsection{The Divisome complex}

Escherichia coli replicates via binary fission. Cells increase in length and split in two by constricting at the middle of the cell where new cell poles are synthesized. The newly 
created daughter cells have an identical shape in both diameter and length. An exact reproduction of the old cell poles at the constriction site is a necessity. The combined activities of hydrolases and penicillin-binding proteins make growth of the sacculus possible. The existing network is hydrolyzed at specific sites to incorporate new peptidoglycan material for elongation and cell pole synthesis.

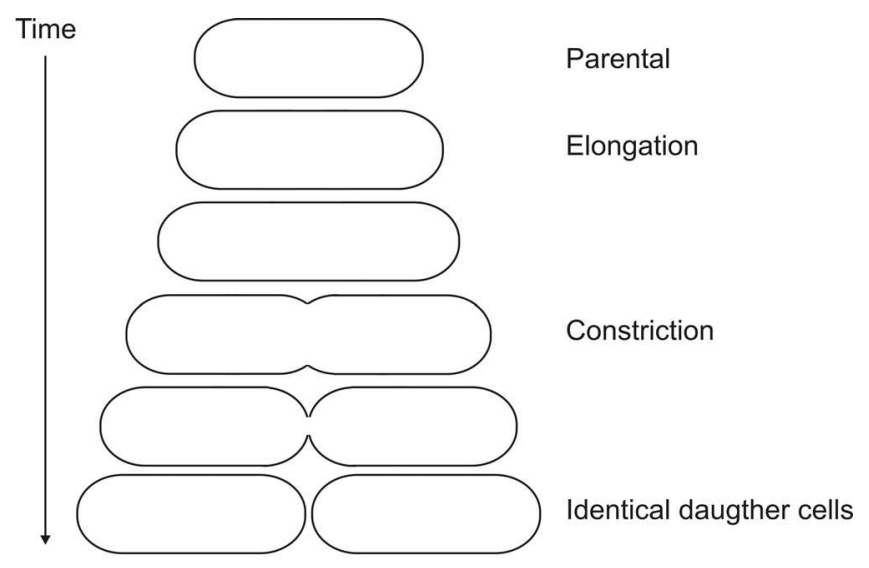

Fig. 2. Escherichia coli cell division. The cells elongate continuously, constriction starts in the middle of the cell producing two identical daughter cells with the same length, diameter and symmetrical poles.

The actual division process requires actions of many more different proteins at all cellular loci being cytoplasm, periplasm and inner as well as outer membrane. Before constriction starts the cell prepares itself by moving the necessary proteins to the constriction site. More than twenty proteins have been identified to be involved in the division process of which at least twelve are essential. Between the latter proteins many interactions are observed and it is therefore hypothesized that a big protein complex is formed referred to as the Divisome (Alexeeva et al., 2010; Di lallo et al., 2003; Karimova et al., 1998; Maggi et al., 2008).

The assembly of the Divisome takes place in two steps that are separated by a delay (Aarsman et al., 2005). FtsZ proteins polymerize and form a so-called Z-ring structure that marks the start of the assembly process. It localizes to the membrane by interactions with the bi-topic membrane protein ZipA and the membrane associated protein FtsA (Hale \& de Boer, 1999). The ring functions as a scaffold for other proteins to attach. Several proteins have been identified that facilitate and support the Z-ring structure and its polymerization. Three of the identified proteins are called Fts $\underline{Z}$ associated proteins (Zap) A, B and C (Durand-Heredia et al., 2011; Hale et al., 2011). The first maturation step ends when FtsE and FtsX arrive. What transpires during the delay is not quite clear, possibly fine-tuning and preparation for the next group of protein that will arrive. In the second or late step a new flow of proteins move to the mid-cell position. These are the membrane proteins FtsK, FtsQ, FtsB, FtsL, FtsW, FtsI, FtsN and periplasmic protein AmiC (Aarsman et al., 2005). Four penicillin-binding proteins localize to the constriction site namely PBP1B, PBP2, PBP3 also known as FtsI and PBP5 (Bertsche et al., 2006; Den Blaauwen et al., 2003; Potluri et al., 2010; Weiss et al., 1997). 
Although PBP1B and PBP3 interact, PBP1B does not play an essential role in cell constriction because it can functionally replace by PBP1A without a change in cell morphology (Bertsche et al., 2006). The function and physical presence of PBP3 is necessary to fully complete cell constriction. PBP2 on the other hand is involved in the constriction process but its function is not essential. Inhibition of PBP2's activity results an increase of the diameter of the new cell poles.

Undoubtly more proteins will be discovered that localize at mid-cell and that will have a role in fine-tuning and regulation of the constriction process. To understand the cell division process at every step, detailed information on where, when and for how long do all these proteins interact is a requisite. From localization studies it has become clear that the division proteins arrive at mid-cell in an interdependent fashion. For instance PBP1B's presence at mid-cell is completely dependent on PBP3 (Bertsche et al., 2006). An alternative view could be that some proteins only move to mid-cell as pre-complexes (Fraipont et al., 2011).

Others are only transiently there like GFP-PBP2 (Den Blaauwen et al., 2003). Because of the dynamic nature of the Divisome, biochemical techniques are not able to give a complete picture of what is going on at every step in the process. Non-invasive in vivo techniques are of great additional value in this field of research.

Variations of bacterial two-hybrid and FRET techniques will be described that have been used to get a better understanding of $E$. coli's cell division interactome. After discussing the techniques results will be presented.

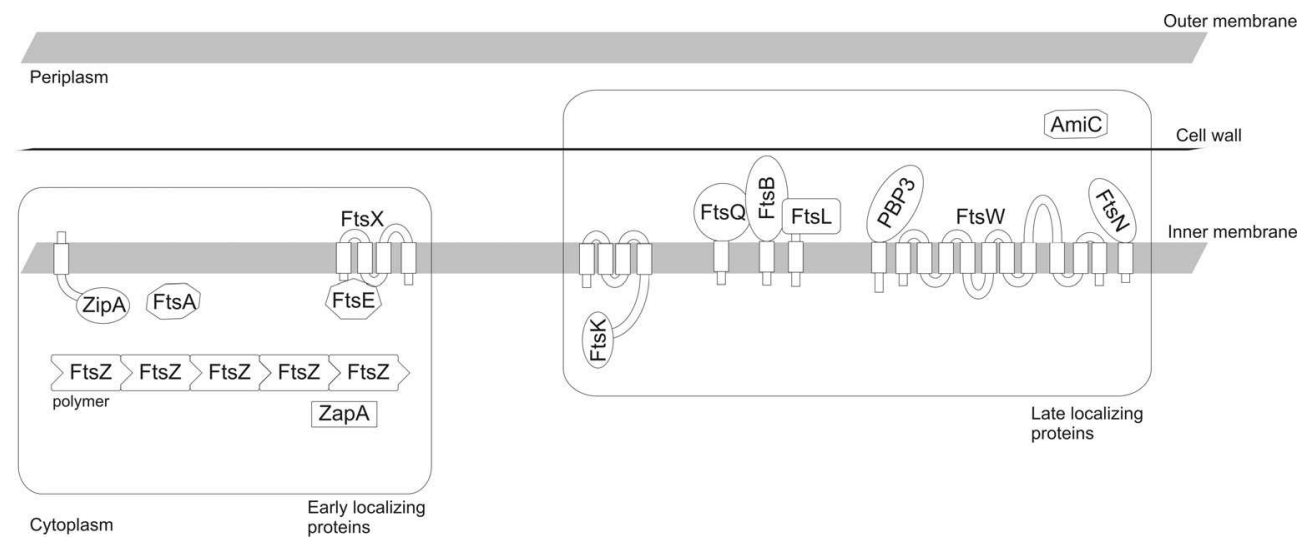

Fig. 3. Some of the cell division proteins identified in E. coli. On the left the early localizing proteins are found with on the right side late localizing proteins.

\section{Bacterial two-hybrid}

\subsection{Introduction}

Studies on protein-protein interactions are essential to fully specify the interactions within a cellular protein network. In the past biochemical techniques like co-immunoprecipitation, 
protein cross-linking and (affinity) chromatography were applied to find interacting protein partners. Although each technique has its specific advantage, often they are laborious and apply harsh wash steps to separate unspecific interactions. Moreover, an interaction in its genuine environment, a living cell is not observed. In a living cell the interaction can be weak or transient and might therefore not be observed with biochemical techniques. In 1989 Fields and Song published a new method to determine protein interactions via a genetic (system) method that was called yeast two-hybrid (Fields \& Song, 1989). This yeast twohybrid technique enabled the researcher to study protein interactions by screening for yeast colonies that were only able to grow on galactose, as the sole carbon source or produce a blue colony when the two proteins of interest called prey and bait interacted. In the yeast two-hybrid method the prey and bait were fused either to an N-terminal or C-terminal domain of the GAL4 protein of yeast Saccharomyces cerevisiae. Upon interaction of prey and bait in the nucleus, the proximity of the N- and C-terminal domain of GAL4 would be sufficiently close to form the complete GAL4 molecule. The hybrid GAL4 protein subsequently activated transcription of the upstream activating sequences for galactose genes (UASg) and the integrated lacZ gene, which codes for the B-galactosidase reporter protein. The $B$-galactosidase protein cuts the galactose sugar bond with 5-bromo-4-chloro-3hydroxyindole. The indole molecule is subsequently oxidized and turns into insoluble blue product, Fig. 7A.

A year later a different genetic method was published using E. coli as a host. Either the Bgalactosidase protein or a bacteriophage immunity assay could be chosen as a screen. In the last case, interaction of the pray and bait leads to a complete $\lambda$ repressor protein, which can inhibit $\lambda$ bacteriophage production and consequently no plague is formed on the plate. The dimerization of a leucine zipper was used as a proof of principle (Hu et al., 1990). The immunity assay has been applied in many publications to investigate protein-protein interactions beside the yeast two-hybrid technique (Blackwood \& Eisenman, 1995; Di lallo et al., 1999a; Longo et al., 1995; Wolfe et al., 1999). Various methods to determine protein or protein-DNA interactions have been published that prevent or allow transcription (Ladant \& Karimova, 2000; Vidal \& Legrain, 1999). Particularly, the switch to use E. coli instead of $S$. cerevisiae provided a clear advantage as E. coli is easier to grow, to transform and to use to make very large libraries (Joung et al., 2000). Another great improvement when working with $E$. coli is that the protein-protein interactions do not need to take place in the cell nucleus to activate transcription, which is a drawback of the yeast two-hybrid system. On the other hand, due to the difference in genetic background, yeast could still be the preferred method for proteins that need eukaryotic folding machineries that are absent in $E$. coli.

Almost a decade later two similar two-hybrid methods were published one for eukaryotes and the other for prokaryotes (Karimova et al., 1998; Rossi et al., 1997), with the latter being possibly the first generally used bacterial two-hybrid method today. What both systems have in common is that they reconstruct a catalytic site that is build from two different domains. The two systems differ in that one activates transcription of the B-galactosidase enzym indirectly via cAMP whereas the other restores the catalytic site of the $B$ galactosidase enzyme upon interaction of prey and bait. The prokaryotic system (E. coli) converts ATP to cAMP, the cAMP receptor protein (CAP) binds substrate and activates transcription of the $B$-galactosidase gene, lacZ. 


\subsection{The bacterial two-hybrid technique}

Today many different variants of the two-hybrid systems have been developed to study protein-protein interactions but also to investigate protein-DNA interactions. These variants are collectively called ' $n$ '-hybrid systems. The one-hybrid system is used to study single protein-DNA interactions, the two-hybrid system to check protein-protein interactions and lastly a three-hybrid system where an RNA molecule brings two proteins together. Initially the systems were developed to screen and identify specific interactions but of course the reversal is also possible, to investigate mutations that result in a loss of interaction. This introduced the terms forward and reverse two-hybrid to discriminate screens that identify an interaction or a disruption (Vidal \& Legrain, 1999). The work discussed here will focus on protein-protein interactions only. In yeast the first and most used two-hybrid method is based on transcriptional activation mediated through direct binding of the prey and bait hybrid complex to the reporter gene. Similar methods have been published for the bacterial two-hybrid systems. Variants have been developed in time for specific purposes or just to improve the system in general (Longo et al., 1995; Strauch \& Georgiou, 2007). In this paragraph, three methods will be presented, two are transcriptional based and one reconstitutes the catalytic site of the reporter. The methods will be explained in more detail followed by a discussion on their pro's and contra's.

\subsubsection{Bacterial two-hybrid via transcriptional repression}

Already in $1990 \mathrm{Hu}$ et al used the $\lambda$ repressor protein to show which residues of the leucine zipper are important for an interaction (Hu et al., 1990). The $\lambda$ repressor is an alpha helical protein that binds DNA upon homodimerization. The amino-terminus of each monomer contains a conserved helix-turn-helix motif that is present in many proteins involved in gene regulation. Dimerization is facilitated by the C-terminal part of the protein. As a dimer the two N-terminal DNA binding domains are sufficiently close together to allow a cooperative interaction of both termini with the nucleotide binding sequence. However, no interaction is observed with the nucleotide binding sequence when the protein is present as a monomer. Castagnoli et al fused the Rop protein to the $\lambda$ repressor. Dimerization of the Rop protein in the cells rendered them immune to $\lambda$ infections (Castagnoli et al., 1994). In 1999 and 2001 a variant of this two-hybrid method to study protein-protein interactions was published (Di lallo et al., 1999a; Di lallo et al., 2001) that combined two different phage repressor proteins, which originated from phage 434 and P22 (Di lallo et al., 2001), Fig. 4. For an increased repression of the promoter, the two operator sequences were built from four alternating half-sites with a 434 followed by P22. The $\lambda$ repressor genes were genetically fused to the prey or bait genes of interest on an IPTG inducible expression plasmid. Only when the prey and bait proteins formed a hybrid protein, the N-termini of P22 and 434 were sufficiently close to merge their forces. Together the helix-turn-helix motifs bind their corresponding DNA sequences and repress the transcription of the reporter protein $ß$-galactosidase.

The constitutively active promoter region responsible for the transcription of the lac $\mathrm{Z}$ gene was a chimeric 434-P22 regulatory region, integrated via cross over in the chromosomal copy of the $g l p T$ gene (Di lallo et al., 2001). The integrating plasmid, called pAPA contained the $g l p T$ gene and crossed over after removal of the origin of replication (Di lallo et al., 1999b). Other bacterial strains can easily be converted to hosts for two-hybrid research by using this specific pAPA plasmid (Di lallo et al., 1999b). 


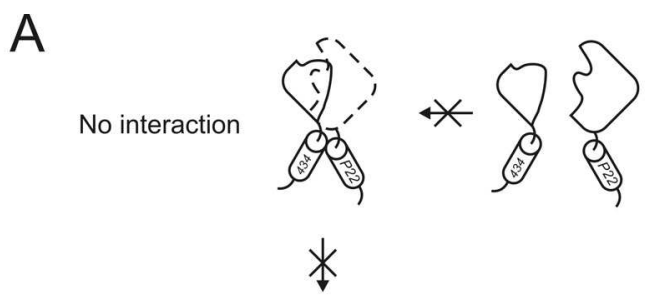

Transcription

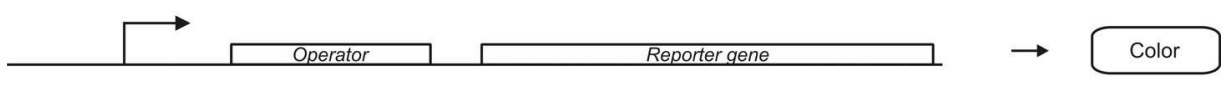

B

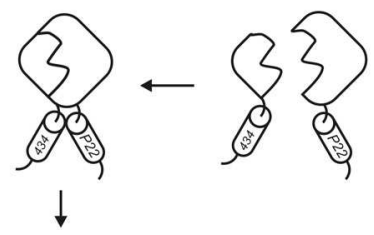

No transcription

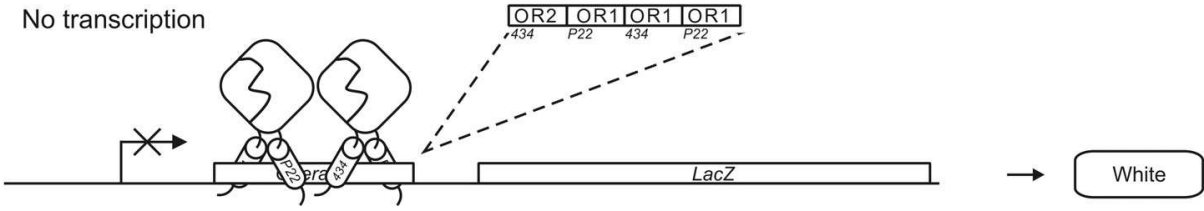

Fig. 4. Bacterial two-hybrid via transcriptional repression. A constitutive active promoter drives expression of the reporter protein $B$-galactosidase. A) If the prey and bait proteins do not interact transcription proceeds. B) Upon interaction a complete repressor protein is formed that inhibits transcription of the reporter.

\subsubsection{Bacterial two-hybrid via transcriptional activation through the cAMP signaling pathway}

The second method described is based on a reconstitution of the E. coli cAMP signal transduction pathway during the interaction of the prey and bait proteins (Karimova et al., 1998). Daniel Ladant showed that the Bordetella pertussis calmodulin-dependent adenylate cyclase (cya) has two interaction sites that bind calmodulin (Ladant, 1988). The adenylate cyclase could be cleaved in two separate domains. The two domains are called T18 and T25 fragments. Mixed in solution these fragments do not induce the low basal calmodulinindependent acitivity that is observed for the full protein. However, the normal activity could be restored when calmodulin was administered. Calmodulin brings both domains close together and allows a reestablishment of the catalytic site. In the absence of calmodulin, the catalytic activity could also be restored when the T18 and T25 fragments were fused to two interacting proteins (Karimova et al., 1998). When these fusion proteins reconstitute adenlylate cyclase activity in an E. coli cya deficient strain, the cAMP-signaling 
pathway is restored, Fig. 5. Adenlylate cyclase hydrolyses ATP to cAMP, which is then bound by the cAMP receptor protein also called the catabolite activator protein (CAP). The formed cAMP/CAP complex subsequently binds to the CAP DNA binding site via a helixturn-helix motif, which induces a change in DNA structure that allows binding of the polymerase to start transcription. The promoter is used to activate transcription of a reporter, like the naturally occurring bacterial genes such as lacZ or mal. Alternatively, an antibiotic resistance gene could be selected as reporter.

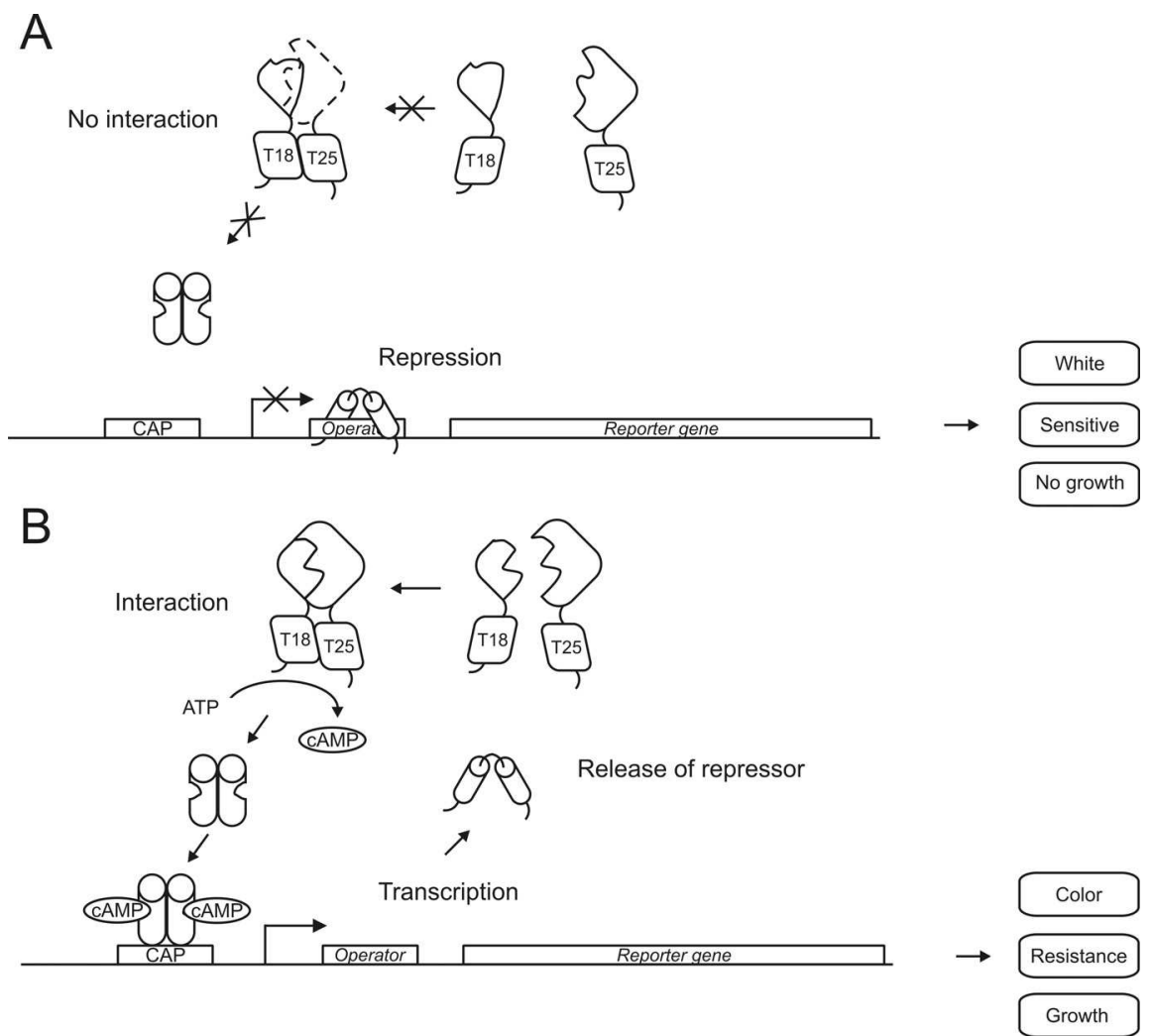

Fig. 5. Bacterial two-hybrid via a cAMP signaling pathway. If cAMP is present in the cell it triggers a conformational change when bound to CAP protein. In the bound state the CAP protein binds its DNA binding site, stimulates polymerase binding and release of repressor protein to promote transcription (RNA polymerase is not shown). An E. coli strain deficient in adenlylate cyclase activity is used to study protein-protein interactions with this method. A) The prey and bait do not interact and no cAMP is produced. No reporter is produced thus no conversion of for example X-gal to indigo blue, no growth on plates when maltose is the sole carbon source and cells are sensitive to the antibiotics. B) When prey and bait proteins interact the two domains of the adenlylate cyclase T18 and T25 are able to dimerize and form a functional catalytic site. In the cell cAMP is produced from ATP, which triggers transcription of a reporter gene that can be lacZ, the mal genes or the gene of antibiotic resistance marker. 


\subsubsection{Bacterial two-hybrid through reconstitution of a ß-galactosidase catalytic site}

Bacterial two-hybrid methods often have more than one option to screen for an interaction. Frequently, a reporter protein is used to detect an interaction between the proteins of interest. With the $B$-galactosidase protein possibly the most popular reporter protein today, applied in both eukaryotes and prokaryotes (Borloo et al., 2007; Wehrman et al., 2002). The method described here is unique not because it uses ß-galactosidase as a reporter protein. It is different because it lacks an 'intermediate' transcription initiation step to produce the reporter protein when the prey and bait interact (Borloo et al., 2007). In the current method the reporter is present in the cell as two separate domains. By reconstituting the active site of the $B$-galactosidase protein, conversion of the reporter product can be measured directly. Possible problems in transcription of the reporter protein are thereby circumvented. In the end of the 1960's it was reported that the B-galactosidase protein could be cleaved in two parts, an N-terminal domain and a C-terminal domain that are called $\alpha$ and $\omega$, respectively (Ullmann et al., 1967). In the crystal structure the protein formed tetramers and showed how the domains interacted. An active catalytic site could be reestablished in vitro from the $\alpha$ and $\omega$ domains (Jacobson et al., 1994; Ullmann et al., 1967). A reconstitution of a functional ßgalactosidase protein was first used as a tool to study interactions in mammalian cells. Later it was successfully applied to investigate protein interactions in the cytoplasm and periplasm of prokaryotes (Borloo et al., 2007).

A

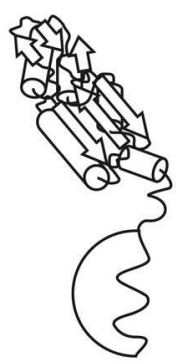

B

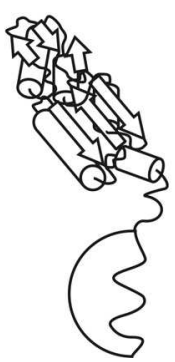

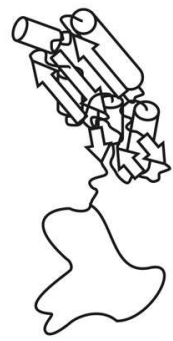

No interaction

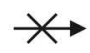

Interaction

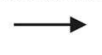

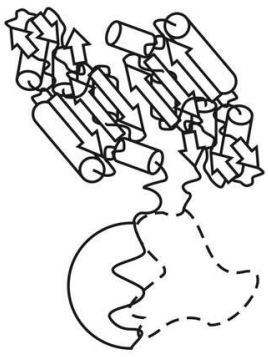

Substrate

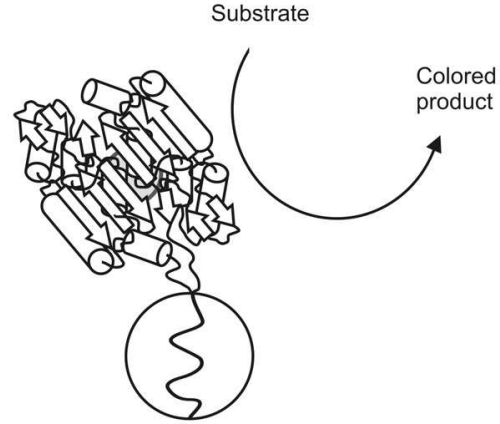

Fig. 6. Bacterial two-hybrid via reconstitution of a catalytic site. B) A fully functional ßgalactosidase reporter protein can be formed from two domains when the prey and bait proteins interact. An advantage is that the reporter protein is functionally active in many compartments of the cell including periplasm. 


\subsubsection{Pro's and contra's of the bacterial two-hybrid method}

The bacterial two-hybrid method like the yeast two-hybrid method is a great accessory tool to determine protein-protein interactions. The great advantage of the bacterial two-hybrid methods is the ease by which an interaction or even better very large libraries with up to $10^{8}$ clones can be screened (Joung et al., 2000). Upon reconstitution of a fully functional reporter protein a signal is produced that is amplified due to enzymatic activity of the reporter. Common examples are conversion of X-gal to indigo blue or ONPG (ortho-nitrophenyl-1sgalacotside) to galactose and the yellow colored ortho-nitrophenol. Plate screening assays mostly use X-gal as a substrate. To compare the interactions between different prey and bait proteins, the amount of active B-galactosidase is measured which is proportional to the rate of ONPG hydrolysis (Miller, 1972). The more functional reporters are formed the stronger the signal. The background signal that has to be determined is the signal produced by noninteracting prey and bait proteins.

A

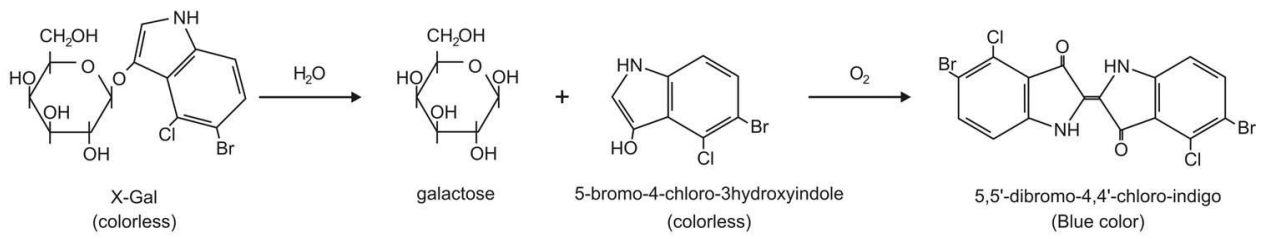

B

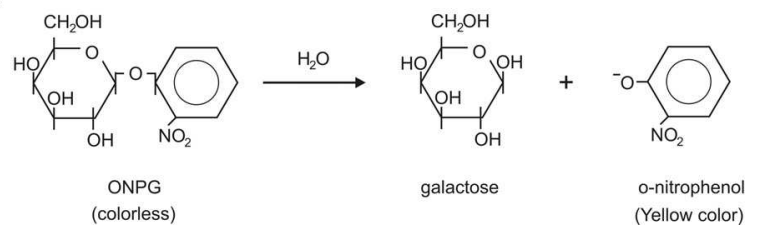

Fig. 7. Two B-galactosidase reporter assays. A) X-gal plate assay and B) the ONPG conversion rate assay to determine the amount of active $B$-galactosidase that represents the number of prey and bait interactions.

However, the results that are obtained need to be interpreted with caution because of potential false negatives and positives in the results. It is difficult to foresee all possible situations and explain them due to the fact that usually not everything is known about the proteins of interest. These false results originate from aspects in the method in combination with characteristics of the protein under investigation. Therefore, it is important to select the most suitable two-hybrid method. Depending on the proteins some methods are more fitting than others. For example, the method of transcription repression is less suitable to study the interaction of membrane proteins because the interacting proteins have to bind a DNA sequence on the chromosome that might not be easily accessible close to the membrane.

Artifacts that create the false positive and negative results can be grouped in two classes related to protein expression and folding and structure. The three methods described, use two low copy number plasmids with a p15A and ColE1 origins of replication, Table 1 . The expression systems are IPTG inducible but differ in promoter strength. Nevertheless, the 
prey and bait fusion proteins are in many cases expressed at levels that are significantly higher than their endogenous levels. Moreover, these systems frequently use wild-type strains to express the fusion protein thus all the fusion proteins produced are extra copies in the cell. This also creates a situation wherein the fusion proteins are competing with the endogenous proteins for an interaction partner. A non-cleavable fusion protein is obligatory to prevent competition between (reporter) domain-less fusion proteins and fusion proteins for a partner. Transient interactions that need the presence of an endogenous protein will therefore be difficult to detect, a positive circumstance when measuring direct interactions.

\begin{tabular}{llll}
\hline & Method 1 & Method 2 & Method 3 \\
\hline Reference & Di lallo et al., & Karimova et al., & Borloo et al., \\
& 2001 & 1998 & 2007 \\
Method & Repressor & Activator & Catalysis \\
Number of plasmids & two & two & two \\
Origin of replication & p15A + ColE1 & p15A + ColE1 & p15A + ColE1 \\
Selection markers & Km, Ap & Cm, Ap & Cm, Cb \\
Strain & R721 & $\Delta$ cya & independent \\
Expression & pLac & pUV5 & ptac \\
IPTG & 100 uM & 500 uM & 20 mM \\
Induction time & 90 minutes & 30 hours & - \\
Background signal & 2500 Miller units & 130 B-gal U/ mg & B-gal activity \pm 1.5 \\
& & & nmol / (min*mg) \\
Reporters & B-gal & B-gal, cAMP, & B-gal \\
\end{tabular}

* As presented in the cited publication. Induction levels and incubation times may be altered by the users of the particular method.

Notes: All the promoters use isopropyl ß-D-thiogalactoside (IPTG) for induction. Selection markers Cm; chloramphenicol, Ap; ampicillin, Km; kanamycin, $\mathrm{Cb}$; carbenicillin. Reporters $\mathrm{B}$-gal; $ß$-galactosidase, cAMP; measure the cAMP concentration in the cell, $\mathrm{Cm}$; resistance against chloramphenicol, lac and mal; for induction of lac or mal genes.

Table 1. Comparing of the methods*

Ideally the fusion protein is able to complement the endogenous protein but this is not always the case or even tested. Some proteins have more than one transiently interacting partner due to post-translation modifications or because they need a chaperone protein for folding. These so-called secondary third party interactions can be disrupted and as consequently lead to a false negative results. Large bulky reporter domains connected to a prey or bait protein can alter their natural movement, functioning and interaction with other proteins. The opposite result occurs when a third party protein brings the prey and bait together causing a false positive result. Therefore it is of vital importance to determine whether the prey and bait fusions are stable, functional, not harmful and do not create other unwanted phenotypes or aggregates.

The structure and the interacting sites of the prey and bait determine if an interaction can be detected with a two-hybrid method. To circumvent problems of steric hindrance the length of linker can be adjusted to introduce more freedom between the protein of interest and its 
reporter domain. A typical linker is for instance $\left(\mathrm{Gly}_{4} \mathrm{Ser}_{3}\right)$. Linkers are constructed from amino acids with small or short side-chains, preferably without charge, which gives flexibility and freedom to move and rotate. It is noteworthy that this steric hindrance is one of the factors that make it impossible to compare the strength of the interactions between different prey and bait proteins. It needs to be kept in mind that the influence of dimerization between reporter domains on the interaction between prey and bait is unknown and can attribute to artificial results. Some interactions are transient and if the interaction of the reporter domains is strong it results in artificial high positive signal. The interaction between the adenylate cyclase domains after reconstituted does not persist when the prey and bait interaction is lost (Dautin et al., 2000). Finally, when a reporter product is formed via a catalytic reaction it is important to provide sufficient substrate that is readily accessible.

In conclusion, the bacterial two-hybrid system is an easy and quick method to determine whether proteins interact. The strength of the bacterial two-hybrid is most likely its simplicity. The interaction is investigated in its natural cellular environment and the amount of reporter product is a measure for how efficient a full functional reporter can be reconstituted. Furthermore, the method provides a limited number of choices. The reporter domains used are fixed, the linker length is often unaltered but can be increased. Frequently the bacterial two-hybrid methods employ the ß-galactosidase enzyme to determine the degree of interaction by looking at the conversion of substrate into colored blue or yellow product. Therefore, being more or less the standard reporter method for the bacterial twohybrids. However, alternative reporters are sometimes offered as with the Karimova method. Additional screening options are growth on MacConkey plates with maltose or lactose as the only carbon source or antibiotic selection. Alternative reporters can be introduced but as a consequence requires some cloning. Complete independence of strain and cellular location is possible when using the Borloo bacterial two-hybrid method. The Karimova method is limited to a cya deficient strain. And the Di lallo method has complete freedom as long as the pAPA plasmid that contains the region for constitutive expression of the lac $Z$ gene is integrated in its chromosome. It is a great advantage to being able to screen a library almost instantly using this technique. However, if little is known about the proteins being studied the results have to interpret with caution. False results can be produced because of steric hindrance, inappropriate linker length or due to third party interactions. Moreover, the expression level of the fusion proteins should be carefully chosen to obtain physiological relevant results. High overproduction conditions will eventually always produce a signal.

\section{Förster Resonance Energy Transfer (FRET)}

\subsection{Introduction}

\subsubsection{Using fluorescent proteins to study movement, localization and interactions in situ}

The first publication on green fluorescent protein (GFP) in the molecular biology had a great impact (Chalfie et al., 1994; Prasher et al., 1992). Characterization of chromophore was even performed before the potential molecular biological application in cells was recognized (Cody et al., 1993; Perozzo et al., 1988; Shimomura, 1979). The protein was functional in 
prokaryotic and eukaryotic cells enabling researchers to monitor protein expression, localization and interactions in living cells (Cubitt et al., 1995; Kain et al., 1995). With the publication of the crystal structure of GFP information about the chromophore environment could be used to perform more educated site-directed mutagenesis studies (Ormo et al., 1996). Improved variants and different colors were created. Additional fluorescent proteins were derived from other marine species. Nowadays, many different fluorescent proteins have been published that almost range the complete visible spectrum. Many proteins are engineered to improve their application in microbiological research. Authentic colors were changed, their tendency to oligomerize was reduced, folding and maturation times were shortened, bleach resistance and brightness increases were reported.

The development of the fluorescent proteins and improvements in the field of light microscopy allowed more quantitative and accurate localization data to be obtained. Confocal microscopy made it possible to determine the co-localization of fluorescent proteins. Unfortunately, the diffraction limit makes it impossible to very precisely determine if proteins are sufficiently close to interact. Proteins with a distance less than $250 \mathrm{~nm}$ were observed as one spot. Switchable fluorescent proteins are of great interest because they make it possible to go beyond this resolution barrier using super-resolution microscopy (Fu et al., 2010). By quickly turning the chromophores on and off independently, the exact midpoint of the light source can mathematically be determined from the Gaussian distribution. The application in localization microscopy introduced the term PALM for photoactivation localization microscopy. Which improved the precision up to $10 \mathrm{~nm}$. Although PALM has a great potential it is an advanced microscopic technique that requires expertise. For measuring fast dynamic processes PALM is not the designated technique, at this moment. An alternative method to measure protein-protein interactions is FCCS standing for fluorescence cross-correlation spectroscopy. A requirement of the technique is that particles move through the detection volume with a minimal speed. Membrane proteins move too slowly. Therefore, interactions between these proteins cannot be determined with FCCS. Förster resonance energy transfer is a well-known applied technique to investigate interactions between proteins; furthermore FRET is not restricted per se to microscopy. For a more complete review describing the history of fluorescent proteins and their biological application within living cells the reader is referred to (Chudakov et al., 2010). This paragraph will focus on application of fluorescent proteins in studying protein-protein interactions using Förster resonance energy transfer. Three FRET techniques will be discussed, two based on an increase in acceptor fluorescence as determined by filter-based method and a spectral-based unmixing method. The third method is based on the measurement of a decrease in the donor fluorescence lifetime.

\subsection{FRET methods and applications}

\subsubsection{Methods to study protein interactions with fluorescent proteins}

In the 1940's the German physical chemist Theodor Förster published several papers describing a process were energy was transferred between two separated molecules with the same dipole-dipole moment (Förster, 1946; Förster, 1948; Förster et al., 1993). Energy was transferred via resonance only when the molecules were in very close proximity. A molecule absorbs energy and gets into an excited state. The energy can be transferred to another molecule, which depends on several factors with distance the most critical one (Lakowicz, 
2006). The process was named after its discoverer Förster's resonance energy transfer (FRET). The energy transfer is not confined to chromophores therefore the name fluorescence resonance energy transfer is incomplete. When working with chromophores it is possible to detect this process by measuring changes in light intensity or in lifetime as will be discussed in the following sections. The chromophore that transfers its energy is the donor and the receiver is the acceptor. See for a description of the basic principles of FRET (Lakowicz, 2006).

A

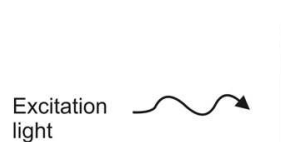
light
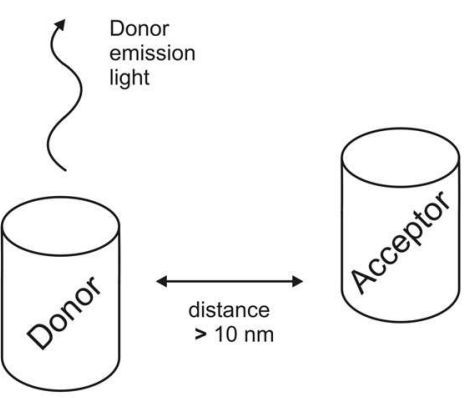

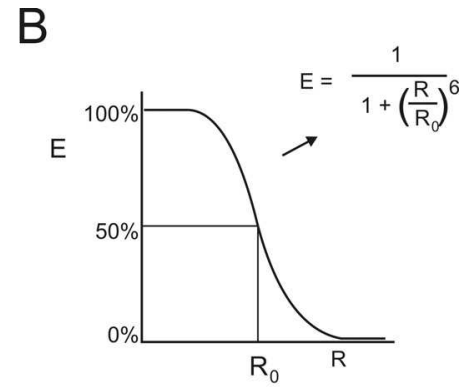

C
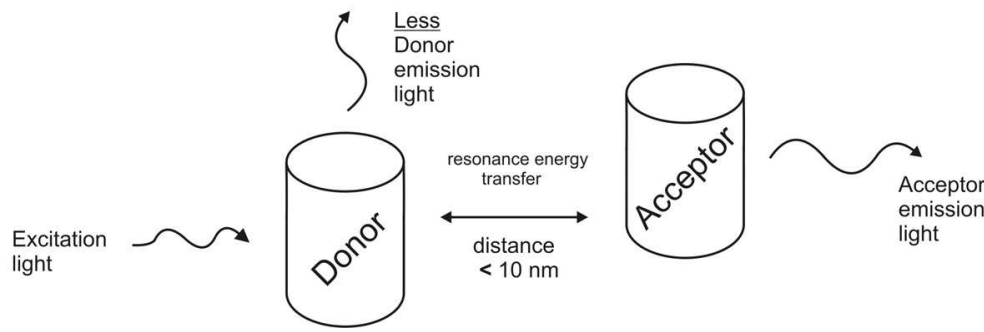

emission or emission light

Fig. 8. Förster resonance energy transfer between donor and acceptor chromophores. A) No FRET when the chromophores are separated more than $10 \mathrm{~nm}$. B) The energy transfer increases rapidly with decreasing distance. C) When FRET occurs the donor light intensity decreases and acceptor emission can be detected. $\mathrm{R}=$ distance between the chromophores, $\mathrm{R}_{0}=$ Förster radius and with $\mathrm{E}=$ the FRET efficiency.

For localization and possibly interaction studies proteins in fixed cells can be labeled with chemical chromophores either directly or indirectly using anti-bodies conjugated to chromophores. Because this does not provide information on protein dynamics fluorescent proteins are a welcome alternative that could overcome this limitation. Without any harmful treatment the localization and interactions of proteins can be monitored. Only oxygen is essential in the cell to complete the formation of the chromophore within the protecting Bbarrel. Several different methods have been developed to determine FRET. The most common methods are based on increases or decreases in fluorescence intensity for the acceptor or donor, respectively. In the first presented method FRET is determined by quantifying the increase in acceptor signal. A more robust method is determining FRET by measuring at a decrease in fluorescence lifetime and this will be described in section 5.2.5. 


\subsubsection{Donor and acceptor fluorescent protein pairs}

The spectral properties of a fluorescent protein are determined by the structure and conjugated pi-system of the chromophore, influenced by the surrounding environment. Fluorescent proteins have the advantage that the chromophore is well contained in a shell of B-sheets that prevent interactions with quenching effects from molecules present in the solvent. Although extreme $\mathrm{pH}$ conditions still affect the protonated state of the chromophore and neighboring side chains in the $\beta$-barrel, large changes in its properties are not expected under physiological conditions. The genes of fluorescent proteins have been cloned and proteins have been purified to obtain the exact data on their excitation and emission spectra. These data sets make it possible to estimate the application potential of each fluorescent protein, a prerequisite for setting up FRET experiments. The important parameters are the extinction coefficient, quantum yield, $\mathrm{pKa}$, lifetime and bleach resistance. The extinction coefficient and quantum yield are a measure of how bright the fluorescence of the protein is. The fluorescence lifetime is the average time a chromophore is in the excited state before falling back to the ground state while emitting a photon. Each chromophore has a different sensitivity to light, known as bleach resistance. A suitable fluorescent protein combination is essential for good FRET measurements and can differ between FRET methods. For FRET to take place the so-called donor and acceptor fluorescent proteins need to overlap in excitation and emission spectra. Specifically, the higher the degree in overlap between donor emission and acceptor excitation spectra the better the energy transfer. An accurate estimation of the efficiency in energy transfer between donor and acceptor is obtained by calculating the Förster radius. This equation calculates the distance at which the donor transfers its energy with $50 \%$ efficiency to the acceptor. The larger the distance the more efficient the energy transfer is. In this calculation factors like the extinction coefficient and quantum yield are included. The angle of the fluorescent proteins, more specifically that of the chromophores determines the efficiency of energy transfer. Because the orientation is difficult to predict, for the calculation of the Förster radius a standard value of $2 / 3$ is taken, assuming random orientations. FRET can be determined by several methods either by looking at the donor or acceptor. From the donor point of view FRET can be measured as a decrease in lifetime or in fluorescence intensity. Sensitized emission is directly measured by looking at the increase in acceptor intensity. More in-depth information about the two proposed FRET methods will be described in the next sections.

\subsubsection{Protein dynamics measured with filter-based FRET}

From an instrumental point of view, a filter-based FRET system is technically the easiest way to determine FRET. Filters block unwanted light thereby controlling propagation of specific excitation and emission wavelengths. An increase in acceptor signal or if possible a decrease in donor intensity is a measure for the amount of sensitized emission. The exposure time should be kept to a minimum to prevent bleaching, which would produce an artificial decrease of the donor fluorescence, mimicking FRET. However, bleach corrections are absolutely essential for calculating exact FRET percentages. A common FRET pair used in experiments is the cyan and yellow fluorescent proteins as donor and acceptor, respectively. Both proteins exist in rapidly folding and quickly mature versions. The proteins have a large spectral overlap. A large overlap in donor emission and acceptor excitation spectra raises the probability of energy transfer and indirectly the Förster radius 
(4.72 nm for ECFP combined with EYFP). The disadvantage is that calculations are necessary to correct for bleed through light and direct excitation of the acceptor. Many different variants of these popular fluorescent proteins have been constructed to improve their applicability. The short folding and maturation times of these fluorescent proteins allow the measurement of FRET in living cells. A successful application for these proteins was in studying protein dynamics during chemotaxis in E. coli (Sourjik \& Berg, 2004; Sourjik et al., 2007). The donor and acceptor proteins were fused to the chemotaxis proteins CheZ and CheY, respectively. It should be noted that an interaction between the CheZ and CheY was proven already but now FRET was used to measure the interaction dynamics of these proteins. Fluorescent proteins were fused to either $\mathrm{N}$ - or C-terminus of the chemotaxis proteins to test which combination would give the highest FRET signal. In accordance with the crystal structure the highest signal was detected when fusions were made to the Cterminal end bringing the fluorescent proteins in the closest proximity of each other (Volz \& Matsumura, 1991; Zhao et al., 2002).

\section{Excitation \& Emission spectra}

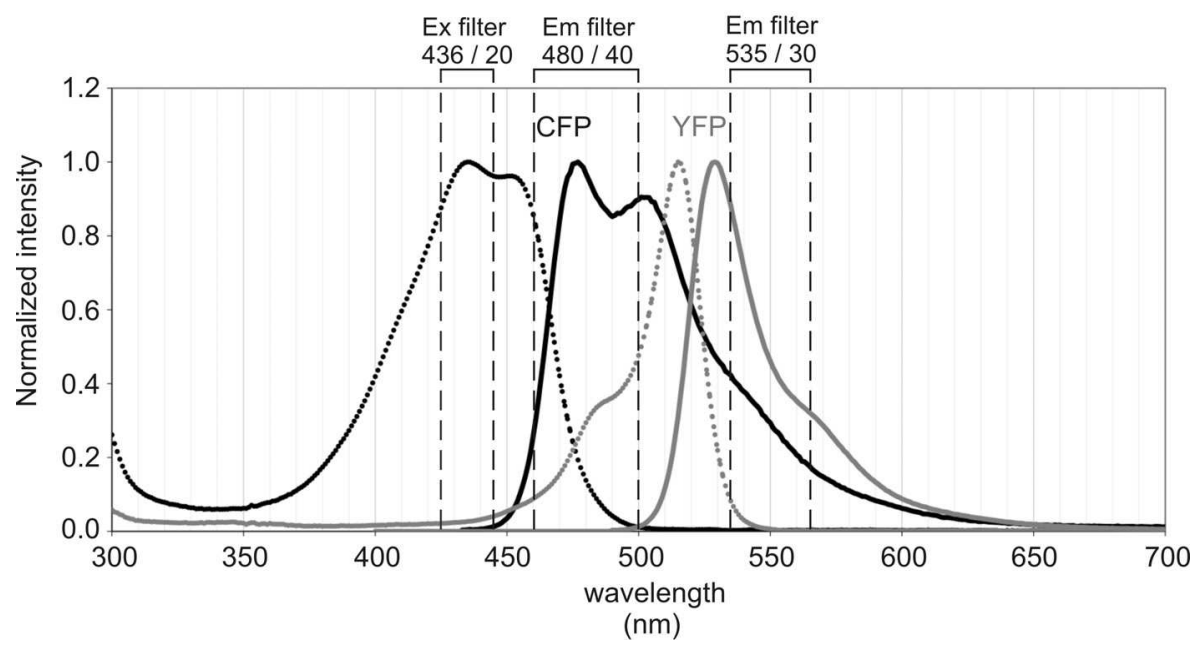

Fig. 9. CFP and YFP excitation and emission spectra. Excitation (dotted line) and emission (solid line) spectra of a CFP and YFP variant including the filters. The normalized spectra shown here have a large overlap. There is overlap in the excitation spectra but also in the emission spectra. Note that CFP covers almost the entire YFP spectrum. The bandpass filters are indicated.

The movement of E. coli during chemotaxis is regulated as follows. Motor proteins drive flagellas in counter clockwise rotation by default. Changes in chemoeffectors in the external environment trigger clockwise rotation of the flagella causing cells to tumble. When they resume the counter clockwise rotation they continue to swim in a new direction to find a more suitable habitat. The chemotaxis pathway of $E$. coli is well characterized; research of the last 40 years resulted in a comprehensive understanding of its mechanism (Vladimirov \& Sourjik, 2009). Here a short description is given to understand the role and interaction of CheY and CheZ in chemotaxis and to be able to fully comprehend and appreciate the 
information FRET can give. Chemoreceptors bind repellents in the environment and promote auto-phosphorylation of CheA a histidine kinase that is bound to the chemoreceptor. The CheA phosphate group is transferred to the cytoplasmically located CheY protein that in its phosphorylated state attaches to the flagella motors to stimulate clockwise rotation. A sufficient pool of CheY is necessary for rapid motor response to changes in the chemoeffector concentrations. Therefore, CheZ dephosphorylates CheY to restore its cellular concentration. An encounter with attractants lowers CheA kinase activity and fewer CheY proteins are phosphorylated. Consequently, the number of CheY-CheZ interactions will decrease which correlates with a drop in sensitized emission signal. The FRET signal is displayed as ratio of YFP to CFP fluorescence intensity. When FRET occurs the CFP (donor) signal will decrease and the YFP (acceptor) signal will increase. By monitoring the ratios of donor and acceptor fluorescence intensity in time in the absence of effectors corrections can be included for fluctuations in the intensity of the excitation light, number of cells observed and movement of the cover slip.

A welcome advantage of this chemotaxis FRET system is the ability to regulate the level of interaction between the proteins by just adding attractant or repellents to the growth medium. Making it possible to more or less switch the interaction on and off.

\subsubsection{Increased sensitivity with spectral-based FRET}

The second method described is the intensity-based spectral FRET method where an increase in acceptor signal is a measure for the amount of FRET. Instead of determining the average intensity of a particular wavelength range like in a filter-based method, a complete spectrum is taken to quantify the amount of donor and acceptor. It can be applied to single data points of a fluorescence spectrum obtained by a spectrophotofluorimeter or to data points from a multiple fluorescence image. The exact contribution of donor and acceptor chromophores can be calculated using the data points for a complete reconstruction of the sample spectrum. As a consequence the FRET efficiency for both donor and acceptor can be calculated from the increase in acceptor signal. The quantification of donor and acceptor in the samples is a great advantage compared to other interaction methods. Because now not only information is obtained on whether the proteins interact but also on the contribution of each protein to the interaction. The contribution of each component can be quantified by 'linear unmixing' of the spectra (Clegg, 1992; Clegg et al., 1992; Murchie et al., 1989; Wlodarczyk et al., 2008). An elaborate unmixing description fitting to our setup can be found in the supplemental information of the corresponding publication and will be explained in less detail (Alexeeva et al., 2010).

In the presented experiments the method is used to investigate interactions at very low expression levels. The sensitivity of the method is exclusively dependent on the amount of photons that can be detected. In a microscopic setup the number of photons used for analysis is limited. For higher sample concentrations or volumes a spectrophotofluorimeter can be good alternative. By using a cuvet more sample can exposed to the excitation light and will thereby boost the photon count. When the number of fluorescent proteins is low, the exposure time is extended to obtain a more reliable spectrum. Real-time measurements will then be difficult especially when emission spectra over a broad range of wavelengths are required. To minimize the level of auto-fluorescence originating from the bacteria, redshifted fluorescent proteins are more suitable for these studies (Alexeeva et al., 2010). The 
A

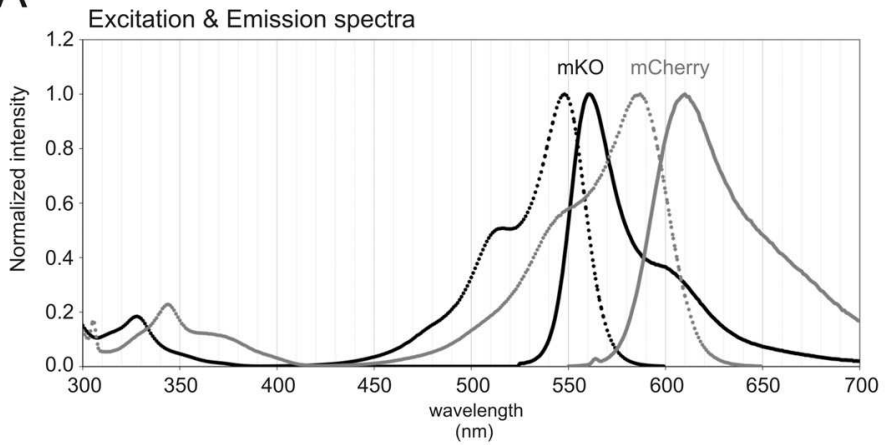

\section{B}
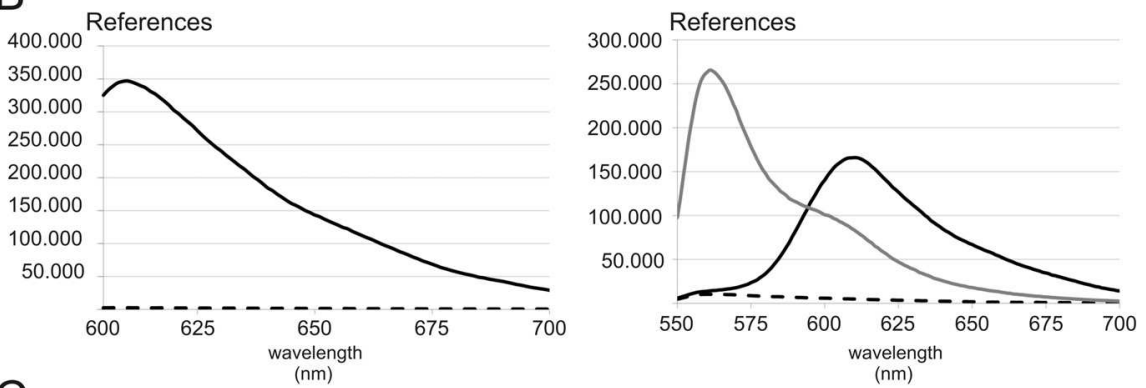

C
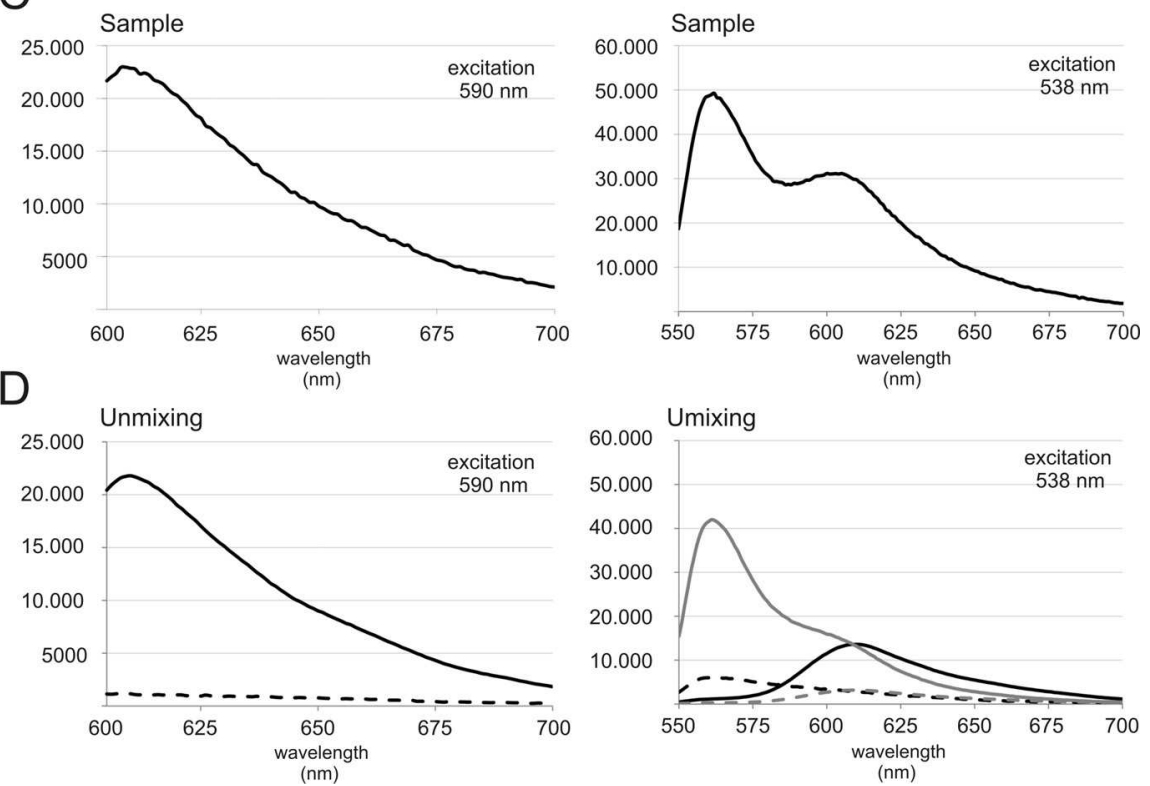

Fig. 10. Principle of spectral FRET unmixing. The excitation (dotted line) and emission (solid line) spectra of $\mathrm{mKO}$ and mCherry are shown in A. Cells were grown to a steady-state and fixed using a formaldehyde:gluteraldehyde solution. After washing of the cells and 
maturation of mKO, two spectra are measured of the samples. Exciting first with $590 \mathrm{~nm}$ to obtain the mCherry spectrum $(605-700 \mathrm{~nm})$ alone. Followed by an excitation wavelength at $538 \mathrm{~nm}$ to detect the $\mathrm{mKO}-\mathrm{mCherry}$ spectrum $(550-700 \mathrm{~nm})$. On the Y-axis of the graph the fluorescence intensity is presented with photons per second with on the $\mathrm{X}$-axis the detection wavelength in $\mathrm{nm}$. The sample spectrum can be reconstructed from the reference spectra when the multiplication factor for each reference is known. These factors are calculated via linear unmixing. For reliable mCherry and $\mathrm{mKO}$ reference spectra the fluorescent proteins are produced in higher numbers compared to the samples. For panels B to D the black lines represent the mCherry profile, the grey line is the $\mathrm{mKO}$ profile, the black dotted line is background with in the Unmixing panel (D) on the right a grey dotted line showing the sensitized emission.

auto-fluorescence signal increases when cells are exposed to more blue-shifted excitation light. A higher auto-fluorescence signal means more emission from excited biomolecules, which is less favorable because it leads to more cellular stress reactions. Therefore, redshifted fluorescent proteins are preferable. In addition the Förster radius $\left(\mathrm{R}_{0}\right)$ is higher when red fluorescent proteins are used compared to blue-shifted proteins (Table 5.1, page 193) (Gadella, 2008). Recall that a high Förster radius means a higher sensitized emission signal upon donor excitation and thus more sensitivity. For these reasons, the red fluorescent proteins $\mathrm{mKO}$ and mCherry are suitable for our research on bacteria $\left(\mathrm{R}_{0}=6.37 \mathrm{~nm}\right)$. The orange fluorescent protein $\mathrm{mKO}$ has a long maturation time of about 15 hours when expressed in E. coli in the contrast to the 15 minutes of mCherry (Shaner et al., 2004). The high brightness of $\mathrm{mKO}$ and its bleach resistance in combination with its spectral profiles make it useful for sensitive measurements but its maturation time makes it useless for realtime measurements. For that reason the samples are fixed. After maturation of the chromophores the spectra of the samples are measured after administering equal amounts of bacteria to the cuvet. In the sample three different components that can produce a signal can be discriminated. The auto-fluorescence and light scattering of the cells together referred to as background signal, and the fluorescence created by the donor and acceptor. The spectral components in the sample spectra depend exclusively on the excitation wavelength that is used. First, mCherry alone is excited to determine the amount of mCherry emission in the sample. The obtained spectrum contains two components; background and mCherry. Subsequently, $\mathrm{mKO}$ is excited which also excites mCherry to some extend. Knowing the amount of mCherry present in the sample, the spectrum can be unmixed in spectra of the background, $\mathrm{mKO}$, direct excited mCherry and sensitized emission by mCherry. The spectral overlap of the $\mathrm{mKO}$ and mCherry proteins makes it inevitable to excite both proteins simultaneously to directly measure FRET. In practice it means that for all the references and samples two spectra have to be measured, starting with the excitation of mCherry followed by the simultaneous excitation of both $\mathrm{mKO}$ and mCherry. The mCherry and $\mathrm{mKO}$ spectra of each sample can be reconstructed by a multiplication of the measured reference spectra and the background spectrum. If more mCherry signal is measured in the $\mathrm{mKO}$ spectrum compared to that in the mCherry only spectrum this is then the sensitized emission and FRET efficiencies can be calculated. Because all the samples are treated identically the method is robust to small changes.

The method has been applied successfully to study interactions between cell division proteins in E. coli at concentrations close to their endogenous expression level (Alexeeva et 
al., 2010; Fraipont et al., 2011). To reach these near physiological expression levels two compatible plasmids are used. The plasmids have a low copy number using the p15A and ColE1 origin of replication. Upstream of the multiple cloning site, a $\mathrm{T}_{\mathrm{RC}}$ promoter is found that allows a lower expression level due to a mutation its promoter sequence (Weiss et al., 1999).

\subsubsection{FLIM-FRET is a robust interaction and localization detection technique}

A completely different method for detecting FRET between a donor and an acceptor molecule is by measuring a decrease in donor fluorescence lifetime. The structure of chromophore determines its lifetime, which is the time an electron stays in its excited state before it falls back to its ground state and emits a photon. Different techniques have been developed to determine the lifetime and both attracted a great deal of interest especially in the field of microscopic imaging. Although microscopy has a long history, the implementation of fluorescence lifetime measurements is relatively young, the publications start at the end of the 80 's. Two methods have been developed simultaneously one termed time-domain and other frequency-domain. Initially frequency-domain was more applicable due to technical limitations at the time to produce short excitation pulses. At the moment both techniques are applied in wide-field and confocal microscopy. Detailed information on FLIM-FRET that handles the technical microscopic setups, the lifetime detection methods with their advantages in application can be found in (Gadella, 2008). In frequency-domain setups the excitation light is intensity-modulated. By using modulated light a shift in phase can be observed caused by the time an electron stays in the excited state, Fig. 11. And due to a loss of energy the amplitude decreases and can be measured. From these differences in phase and modulation the corresponding lifetimes are calculated. A time-domain lifetime setup is more easily explained. A pulsed laser excites a chromophore and the time that passes until a photon is measured in the detector is the lifetime of the chromophore. The time a photon needs to go from the initial excited state to emission and hitting the detector is a statistical random process. The moment a chromophore emits its energy via production of photon is highest just after the pulse excitation and decreases rapidly in time; therefore the lifetime is an average value. The close proximity of an acceptor offers an additional path for the excitation energy to go. In practice it means that the electron stay shorter in the excited state decreasing the average lifetime. Remember that the distance between the donor and the acceptor molecule strongly affects the likely hood of FRET, which is proportional to the decrease in lifetime of the donor chromophore.

In the research field of cell division FLIM-FRET has been used to investigate the roles of SsgA and SsgB during sporulation of Streptomyces aerial hyphae (Willemse et al., 2011). These proteins co-localize together with FtsZ, both SsgA and SsgB move to mid-cell in the respective order before FtsZ arrives. To find out whether the proteins interact FLIM-FRET was applied. Fluorescent protein fusions of eGFP and mCherry were constructed. The fusion proteins showed full complementation of the deficient strains. The fusion genes replaced the endogenous gene; expression was therefore under control of their authentic promoter. A decrease in the eGFP lifetime was observed with fusion protein combinations SsgA and SsgB, and SsgB with FtsZ.

In the previous section a time-domain FLIM microscopic setup was used. In the past we have applied a frequency-domain FLIM setup to proof that the spectral FRET method 
produces reliable data. Instead of using GFP, mKO was used as the selected donor. The interaction between FtsZ molecules was studied by fusing $\mathrm{mKO}$ and mCherry to its aminoterminus. The fluorescence lifetime of $\mathrm{mKO}$ was $2.89 \pm 0.05 \mathrm{~ns}$ in cells coexpressing unfused $\mathrm{mKO}$ and mCherry. When $\mathrm{mKO}$ and mCherry were fused to FtsZ, the mKO fluorescence lifetime was decreased to $2.69 \pm 0.03$ ns corresponding to a FRET efficiency of $7 \%$ (Alexeeva et al., 2010).

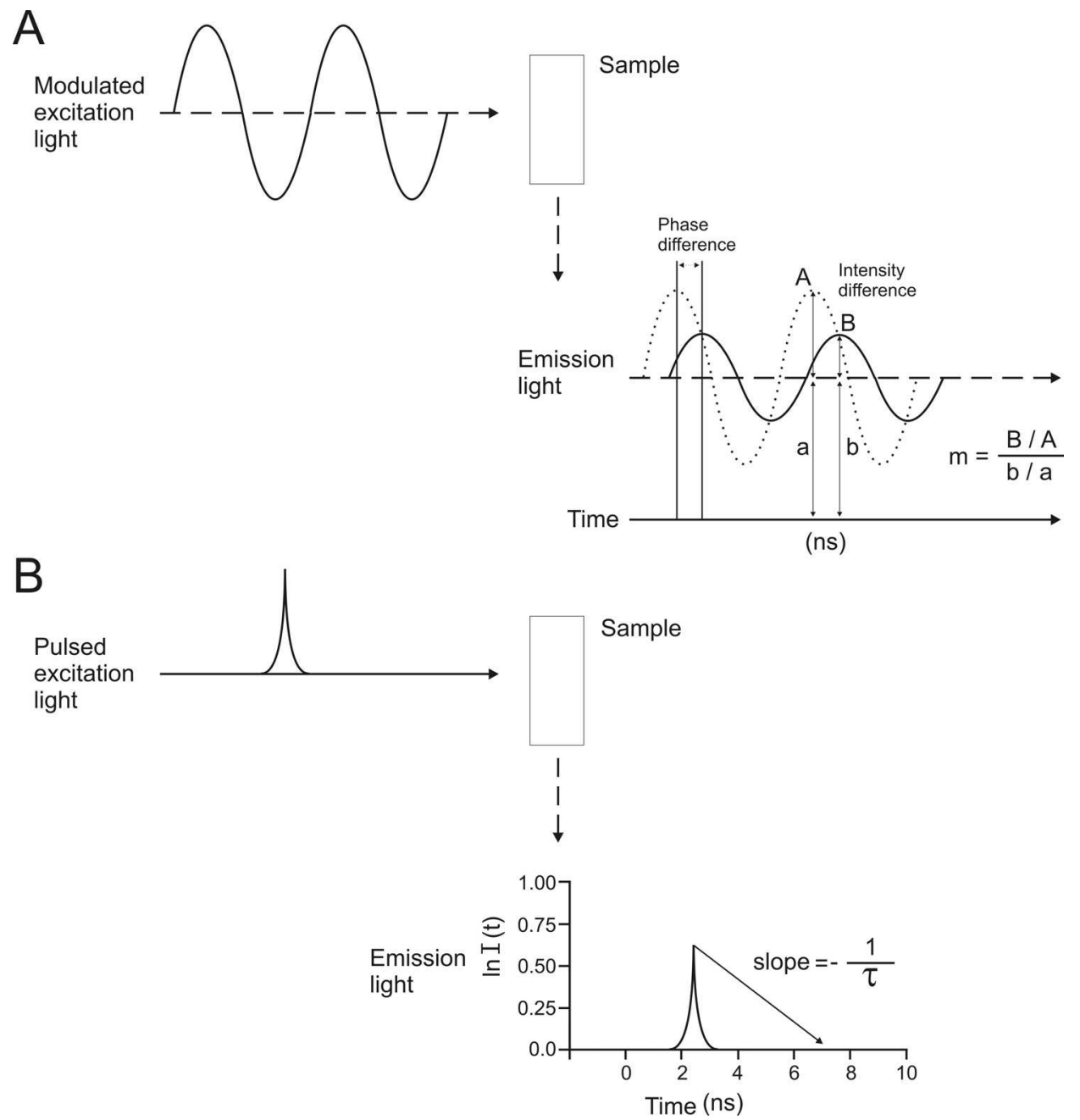

Fig. 11. Frequency-domain and time-domain FLIM. A) The frequency-domain measurements. In the picture presenting the emission light two signals are presented. The solid line is the emission signal and the dotted line the source excitation light for a comparison. From both the phase and modulation a lifetimes can be calculated. B) A schematic presentation of a time-domain measurement where the lifetime $(\tau)$ can be calculated from the slope. 


\subsubsection{Pro's and Contra's of lifetime and intensity based FRET methods}

The application of fluorescent proteins in research allows you to observe movement and localization of proteins and study interactions with their partners. The ability to detect emission light makes it even possible to quantify data, study interactions real-time and calculate the dynamics. This provides considerable extra information compared to the bacterial two-hybrid method. However to obtain reliable FRET data, a clear understanding of the instrumental setup and a careful selection of fluorescent proteins is a necessity. Some crucial points will be discussed to provide the reader with insight in bottlenecks that can be encountered when applying a FRET method.

\subsubsection{Instrumental settings and fluorescent protein selection}

Before applying fluorescent proteins to studying protein localization and protein-protein interactions, several factors need to be taken into account. These factors have a biological, instrumental or mathematical origin when additional calculations are necessary. It is important to understand the limitations of the instrumental setup that being either a microscope or spectrophotofluorimeter. This includes knowledge on the properties and contributions of additional materials like filters. It is needless to mention but the instrumental setup should be in good conditions to reach maximum sensitivity. For a comprehensive understanding about the technical microscopic setup the reader is referred to (Gadella, 2008).

The biological factors that affect the results of the experiment originate from the use of fluorescent proteins, the linkers to fuse them to the prey and bait combined with the necessary expression tools. The barrel of a fluorescent protein is in general not interacting with other intercellular proteins and makes it therefore a very suitable protein for research. However, extended exposure of the chromophore to excitation light results in photobleaching and production of reactive oxygen species (Dixit \& Cyr, 2003). Reactive oxygen arises when the energy from the (triplet) excited state of the chromophore is transferred to molecular oxygen. As a consequence the produced reactive oxygen species can lead to damage of important cellular molecules like proteins, lipids, nucleic acids etc. Additionally damage might be introduced due to a change in the redox homeostasis. Bright fluorescent proteins are desired because they decrease exposure time giving few reactive oxgen species. Therefore, the theoretically most suitable fluorescent proteins should be selected that match with the instrumental and experimental setup. Frequently the behavior of a fluorescent protein varies with organism and deviates from the reported characteristics. Often these differences arise due to dissimilar biological conditions and instrumental setups. The fluorescent protein pair should be tested in host organism using the experimental setup to learn how it behaves in the cell.

For the spectral FRET method $\mathrm{mKO}$ was used as a donor and was published to have a relative long maturation half time of 4.5 hours (Karasawa et al., 2004; Shaner et al., 2008). In $E$. coli the protein needed an even longer maturation time of \pm 15 hours to become fluorescent. By fixing the cells with a formaldehyde:gluteraldehyde solution the biological condition is frozen but it was unclear how this would affect $\mathrm{mKO}$ behavior. The fixation did proof not to be a problem for $\mathrm{mKO}$ maturation and fluorescence. Some fluorescent proteins are sensitive for fixation and lose some of their characteristic. An example is YFP that dramaticly decreases in brightness after fixation. 
Many different fluorescent proteins are published with colors ranging the complete visible spectrum. The large set of fluorescent protein should give enough options for selecting the right pair for your setup.

Fluorescent proteins are fused at the amino-terminus or carboxy-terminus end but in some cases it can also be placed in a loop (Bendezu et al., 2009). Often the fluorescent protein and protein of interest (prey or bait) are fused to each other by an amino acid linker. The length of the linker needs to be adjusted to place the fluorescent protein there where it minimizes interference with the biological function of the protein of interest. To verify the functionality of the protein fusions, a deficient or depleted strain can be complemented and the normal localization of the protein can be detected. The aim should be to bring the fluorescent proteins of prey and bait in the closest proximity upon interaction. A crystal structure can help and speed up finding the correct linker length for the fusion. The risk encountered when fusing a fluorescent protein to a prey or bait protein is almost identical as described in the bacterial two-hybrid section. Competition of the fusion protein with wild-type proteins can be expected and therefore working with deficient strains is advised. Moreover, the amount of the fusion protein in the cell should be compared with the non-fused protein to detect differences in expression or biological stability. The characteristics of the linker can attribute significantly to functionality of the fusion protein thereby contributing to the stability of the fusion protein.

The three described FRET methods use completely different instrumental setups and fluorescent proteins to reach their goal, all having their own specific quality. The first method measures dynamics, the second method quantifies the level of FRET and the FLIM method is robust and semi-quantitative and suitable for single cell studies.

For measuring a dynamic process, a fast folding and bright fluorescent protein pair such as CFP and YFP is ideal. Changes in fluorescence intensity due to FRET will than easily be picked up. The application of CFP and YFP in studying the interaction between CheY and CheZ proteins shows how effective this combination is (Sourjik \& Berg, 2004; Sourjik et al., 2007). A pitfall in the application of filter-based FRET is the misinterpretation of intensities for donor and acceptor levels. An overlap in the excitation and emission spectra of the donor and acceptor chromophore can lead to a process called bleed-through or leak-though. In the example with CFP and YFP, both are directly excited with the donor excitation wavelength (Sourjik et al., 2007). Fortunately, the acceptor is only excited to a minor extent and therefore hardly contributes to the FRET signal. Direct excitation of the acceptor should be kept to a minimum because an excited acceptor cannot absorb energy from an excited donor molecule. Two detection channels are used one for the donor and one for the acceptor. The FRET efficiency can be calculated when the fluorescence intensity is measured for the donor and acceptor when no interaction is taking place $\left(\mathrm{FP}_{0}\right)$. The change in fluorescence intensity for each fluorescent protein $(\Delta \mathrm{FP})$ by $\mathrm{FP}_{0}$ gives the FRET efficiency assuming that the autofluorescence and bleaching is corrected for. However, for quantitative FRET measurements using a filter-based FRET method, many more additional factors have to be taken into account (see chapter 7 of FRET and FLIM techniques (Gadella, 2008)) when a noninteracting condition cannot be created and/ or measured. As pointed out earlier it is very important to know how the selected fluorescent proteins behave under the experimental conditions. For example photo-conversion of YFP is observed during photobleaching leading to a CFP emission signal upon excitation as reported by some but contradicted by 
others (Thaler et al., 2006; Valentin et al., 2005). Finally, to be able to follow a dynamic process for a very long time the fluorescent proteins should have a high bleach resistance. YFP for instance tends to be bleached relatively quickly (Griesbeck et al., 2001; Kremers et al., 2006).

For the analysis of low abundant division protein of E. coli comparable low endogenous protein expression levels were desired. The fluorescence emitted from a single cell was at the detection limit of the microscopic setup. Therefore, a spectrophotofluorimeter has been adopted instead to measure the fluorescence of many bacterial cells simultaneously. The information on localization was obtained in separate experiment. FRET calculated from a single wavelength is prone to false results. It is not always clear if the increase in fluorescence intensity of the acceptor originates from FRET. As mentioned earlier for YFP, photo-conversion induced by the excitation light might be responsible for the increase in acceptor but will not be recognized as such. More insight is obtained by the measurement of complete donor and acceptor spectra. The production of a sensitized emission signal should lead to an increase in the acceptor spectrum. If the increase in addition changes the shape of the acceptor spectrum it can be identified as an artifact. This can be especially important when working with low expression levels in a high auto-fluorescence spectral area. Because bacteria hardly give any auto-fluorescence in the red-spectral range, the orange fluorescent protein $\mathrm{mKO}$ and the more red-shifted mCherry were selected for the spectral FRET method. The sensitized emission is only a fraction of the emission of both proteins and therefore a low signal to noise ratio will improve the precision and reliability of the FRET signal. The bacteria behave as particles in the excitation light which causes considerable lightscattering. The unwanted light scattering polluting the emission spectrum is removed by use of specific emission filters that block the scatter light.

It is noteworthy that when working with the spectrophotofluorimeter bacterial cultures need to be grown as much as possible to a steady-state before the experiment can be started. In a steady-state culture the cells have on average a constant mass indicating that their mass increases at the same rate as their cell number. Consequently, the cells have a homogeneous metabolism and morphology that will provide a constant auto-fluorescence background in the cells. This is essential for the unmixing of the spectra, which assumes that a multiplication of the background, $\mathrm{mKO}$ and mCherry reference spectra determine the shape and magnitude of the measured spectrum.

Using spectra to determine the amount of each reference in a sample has advantages. By carefully selecting the fluorescent protein pair and their excitation and emission wavelengths the sensitivity can be further improved. The greater the spectral difference between the references the more easily and accurately each contribution can be calculated to reconstitute the sample fluorescence profile. Excitation at different wavelengths changes the intensity but not the shape of the emission spectra of $\mathrm{mKO}$ and mCherry. However, the shape of the background spectrum is dependent on the excitation wavelength and can therefore be selected. The freedom in selecting the excitation wavelength has some boundaries. When exciting the donor molecule the emission signal should be as high as possible with as little as possible direct excitation of the acceptor.

Fluctuations in the fluorescence intensity or photo-conversions of chromophore do not affect the fluorescence lifetime measurements making this method more robust. The time-domain 
and the frequency-domain methods have both their own advantages. Time-domain measurements can be relatively time consuming compared to frequency-domain especially when fluorescence intensity is low. On the other hand quantitative FRET percentages can more easily be retrieved from time-domain data. The detection speed of the frequencydomain method makes it more suitable to study protein dynamics. Preferably the lifetimes of the background, donor and acceptor should differ substantially. When possible, the lifetime of the background signal should be higher compared to that of the donor protein. Because it excludes the possibility that the two lifetimes overlap when the lifetime of donor is reduced due to FRET. To monitor real-time dynamics still the brightest fluorescent proteins are most desirable!

\subsubsection{Interpretation of results}

The major advantage of fluorescent proteins in cell biology is the direct representation of where a protein is in a living cell. A different but important advantage is that the proteins do not react with each or other components in the cell. The lack of affinity between fluorescent proteins makes them perfect to study protein-protein interaction via FRET. Fluorescent proteins have a relative large size of about $27 \mathrm{kDa}$ for green fluorescent protein (GFP). A fusion of GFP to a smaller protein can alter its natural behavior significantly. And thus the ability of a fusion protein to complement a deficient strain is an important measure to test if fusion proteins can functionally replace the wild-type. In addition the stability of the fusion protein in the cell should be checked. Cleavage of fusion protein can reproduce a wild-type version product that can compete with its partner fusion protein thereby decreasing the FRET percentage. Conditions in which the fusion protein is present in the cell in levels that exceed the normal numbers should be prevented. High expression conditions can introduce artifacts due to oligomerization of the fluorescent proteins or create bystander FRET. Oligomerization of fluorescent proteins can takes place in the sub-millimolar range $(0.1 \mathrm{mM})$, which is a concentration that can be easily reached when expressing membrane proteins in relative high amounts. Non-dimerizing fluorescent proteins have been created that only dimerize at very high concentrations that are almost not achievable intra-cellular. Bystander FRET is created by overproduction of the fusion proteins in the cell and as a result they come into close contact due to molecular crowding. Both situations have to be avoided. Non-interacting fusion constructs can be used as negative controls for these artificial interactions and should be added to the experiment.

Some interactions are transient or only take place in a single locus with limited space and are reasons why expression conditions should be carefully controlled and selected. Although a fusion protein can complement a deficient strain, its localization might not always be identical to the endogenous protein. A sign that there is a disturbing effect originating from the fusion with linker and fluorescent protein. Unfortunately, working with a deficient strain is not always possible. Therefore, a slight overexpression is preferred above underexpression that should be avoided at al times. In a wild-type strain fused and unfused proteins will compete for an interacting partner. To outcompete the wild-type protein a slightly higher concentration of fusion proteins is recommended.

The list of checkpoint and controls that have to be taken into account seems to be long but the advantages greatly outweigh the work that is involved. Not many other techniques can produce reliable data from a living cell in real-time. Representing interactions and dynamic process as they take place. 


\begin{tabular}{llll}
\hline & Method 1 & Method 2 & Method 3 \\
\hline Reference & Sourjik \& Berg, & Alexeeva et al., & Willemse et al., 2011 \\
& 2004 & 2010 & \\
Interaction & Dynamics & Fixed & Both \\
Method & Filter & Spectral & Lifetime \\
FRET determination & Intensity & Intensity & Lifetime \\
Plasmids & two & two & Chromosomal \\
Origin of replication & p15A + ColE1 & p15A + ColE1 & - \\
Selection markers & Km, Ap & Cm, Ap & Am \\
Strain & independent & independent & independent \\
Expression & pTrc, pAra* & pTrc-down & Natural promoter \\
IPTG / arabinose & 50 uM / 0.01 \% & 10 or 15 uM & - \\
Induction time & 4 hours & 6 hours & - \\
\hline
\end{tabular}

Notes: fluorescent proteins used cyan fluorescent protein (CFP), yellow fluorescent protein (YFP), green fluorescent protein (eGFP) and mCherry $(\mathrm{mCh})$. The pTrc promoters use isopropyl $\mathrm{B}$-D-thiogalactoside (IPTG) for induction with arabinose for the promoter. Selection markers $\mathrm{Cm}$; chloramphenicol, Ap; ampicillin, $\mathrm{Km}$; kanamycin, Am; apramycin. * = the number of plasmids used in articles differs (Sourjik \& Berg, 2002; Sourjik \& Berg, 2004). The former used two and the latter one plasmid with a Trc promoter. The two plasmids were contained an arabinose and Trc promoter.

Table 2. Comparison of methods

\section{Conclusion}

\subsection{Comparing FRET and bacterial two-hybrid}

After going through the method sections it becomes immediately clear that there is a big difference between the bacterial two-hybrid methods and the FRET methods. The bacterial two-hybrid methods are verily easy and straightforward in providing an answer. Additional technical expertise is required when applying FRET in research. But the use of fluorescent proteins provides more information about the localization of the interaction and possibly also information can be gathered on the dynamics between the proteins, this in contrast to the bacterial two-hybrid. For both the bacterial two-hybrid and FRET method a wild-type behavior of the fusion protein is desired. Complementation experiments using deficient strains are effective controls to see if the fusion protein fulfills these requirements. The information obtained on the localization of the fusion proteins is lacking with the twohybrid method. Fractionation experiments can only partially compensate for the difference between the two methods.

Another difference is the use of the linker. Linkers are used in both systems to stimulate the natural wild-type behavior of the protein in the cell. For the bacterial two-hybrid method extra freedom in movement for the reporter domain is less harmful compared to the FRET method. In a two-hybrid system, a reporter protein becomes complete upon interaction of the prey and bait. The fully functional reporter protein facilitates, direct or indirect, synthesis of a reporter product that continues to pile up and thereby amplifies the signal. With fluorescent proteins the situation is completely different. They have no affinity for each other and more freedom will result in more movement decreasing the chance that the proteins will remain or be close to another. Therefore, the sensitized emission signal will become weaker and harder to detect which make dynamic measurements impossible. The 
reporter methods are responsible for why the bacterial two-hybrid method produces higher false positives and the FRET method more false negatives. Endogenous protein expression levels for the fusion proteins should be maintained as much as possible. Unfortunately, high expression levels are frequently observed within use of the bacterial two-hybrid method but should be avoided at all times. Whether the bacterial two-hybrid or FRET method will be employed is completely dependent on the question that needs to be answered. A FRET experiment will gain a more comprehensive answer to what is going on but tends to be more time consuming.

\subsection{Interactions and use in cell division research}

In the last part of this chapter, an overview of several publications will be presented to illustrate the variation found between the interactions of $E$. coli cell division proteins. The proteins investigated differ in structure, function and cellular location; they are present in the cytoplasm and the inner-membrane. Some of these cell division proteins show considerable movement during the cell cycle. Several interactions are believed to be only transient, taking place only at mid-cell when new cell poles need to be synthesized. Examples of interacting cell division proteins are the FtsZ proteins that together form a polymer, which interacts with membrane proteins FtsA and ZipA. ZapA proteins bind to the polymer thereby stabilizing the structure. The membrane proteins FtsK, FtsB, FtsL and FtsQ move to the mid-cell position. Subsequently, the FtsW-PBP3 precomplex is recruited to the septation site where also FtsN arrives. More proteins are thought to be involved in the actual division process, like the periplasmic protein AmiC that is essential for the cleavage of the septum during the constriction process. Current thinking suggests that many of these proteins together form a big complex at mid-cell, called the Divisome. With multiple complexes spread across the Z-ring structure to facilitate the constriction of cell.

The division of the cell is a delicate process that needs carefully regulation. The copy number of each specific division protein in the cell is balanced. Overproduction of a cell division protein disrupts this balance which causes cell division defects like cell filamentation. Bacterial two-hybrid and FRET methods have been employed to study the interactome of the division proteins. Three bacterial two-hybrid methods are presented; two using the Di lallo method and one using the Karimova method (Di lallo et al., 2003; Karimova et al., 1998; Maggi et al., 2008). These bacterial two-hybrid results are compared with that found using spectral FRET method described in two papers, Alexeeva et al and Fraipont et al, Fig. 12. Several interactions are reproduced and are therefore most likely true. However, also contradicting results are found when applying these different methods, which can originate from the technique. In the Di lallo method an interaction between prey and bait is only observed when the dimer binds the DNA operator site. Integral membrane protein cannot easily reach DNA sequences compared to proteins dwelling in cytoplasm. False results are not unusual when applying these techniques being false positive for the bacterial two-hybrid method and false negative for the FRET method. The differences may arise due to the method but might also be caused through differences in the expression levels. Di lallo and Karimova use different promoters and induction concentration. It would be very interesting to determine if the bacterial two-hybrid and FRET experiments yield the same results when the expression and bacterial growth conditions are kept identical, preferably native protein concentrations. 
Bacterial two-hybrid

A

Transcriptional repression

Di lallo

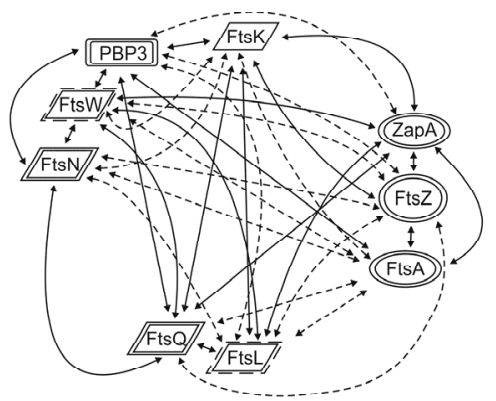

C

Transcriptional activation

Karimova

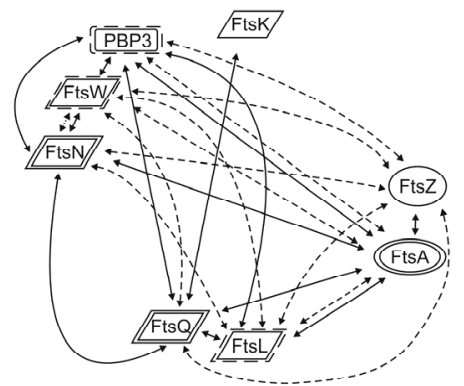

FRET

E

Spectral FRET - intensity based

Alexeeva

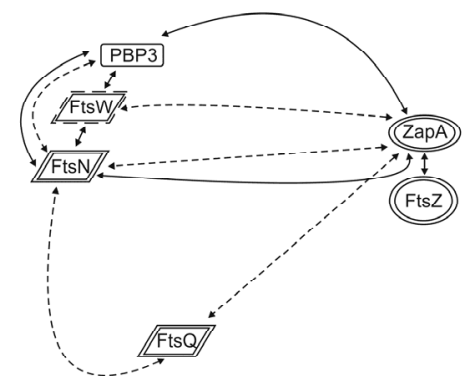

B

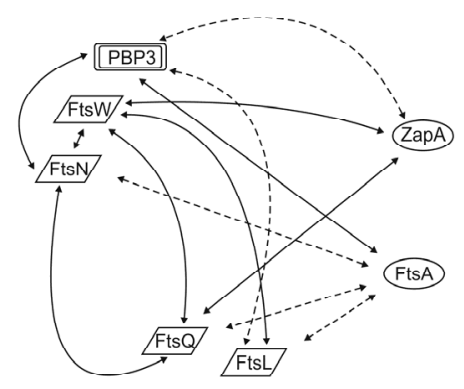

D

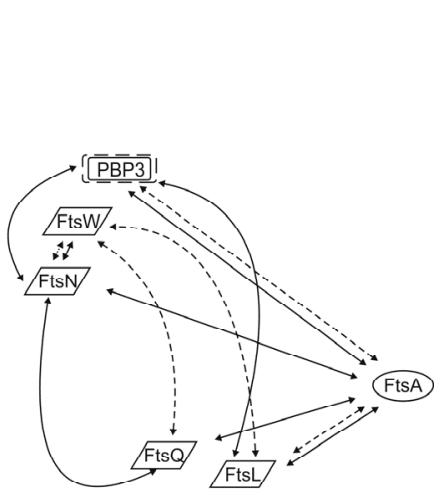

F

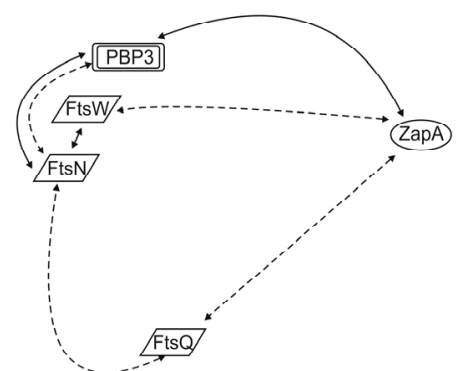

Fig. 12. A comparison of bacterial two-hybrid and spectral FRET results found for cell division proteins interactions. The solid lines represent an interaction between two proteins 
and when no interaction was found the proteins are connected by a dotted line. Panels A, C and $\mathrm{E}$ show all the interactions studied and B, D and F represent the differences. A double line around name of the protein indicates that the protein is self-interacting. All the rectangles represent membrane proteins; the one with a straight corner is a penicillin binding protein. The circler proteins are present in the cytoplasm.

Although an interactome scheme can be constructed still many questions remain. Isolation of a complete Divisome complex has not been successful. With the current knowledge it can be speculated that isolation of a complete Divisome complex might prove to be too difficult due to weak and transient interactions. For now structural information of the Divisome complex is lacking. Fortunately more knowledge on the interactome and structure of the Divisome can be gained using bacterial two-hybrid and FRET techniques. Bacterial twohybrid methods can be used to quickly screen many protein mutants to harvest information on interaction sites, like performed for FtsQ and PBP3 (FtsI) (D'Ulisse et al., 2007; Karimova et al., 2005). Protein-protein interactions in the periplasm can be analyzed using Borloo bacterial two-hybrid method. And the described FRET techniques can provide valuable information on dynamics, movement and localization to improve our understand about the (dis)assembly, mechanism and structure of the Divisome complex.

\section{Acknowledgments}

This project was supported by the Dutch NWO 'Van Molecuul tot Cel' programme grant ALW 805.47.200 and by a Vernieuwingsimpuls grant 016.001-024 (T.d.B.) and by the European Framework Programs DIVINOCELL HEALTH F3-2009-223431 (R.v. d.P). We would like to thank Eelco Hoogendoorn and Joachim Goedhart for fruitfull discussions and Mark Hink for reading the manuscript.

\section{References}

Aarsman, M. E.; Piette, A.; Fraipont, C.; Vinkenvleugel, T. M.; Nguyen-Disteche, M. \& den Blaauwen, T. (2005). Maturation of the Escherichia coli divisome occurs in two steps. Mol.Microbiol., Vol. 55, No. 6, pp. 1631-1645, 0950-382X; 0950-382X

Alexeeva, S.; Gadella, T. W.,Jr.; Verheul, J.; Verhoeven, G. S. \& den Blaauwen, T. (2010). Direct interactions of early and late assembling division proteins in Escherichia coli cells resolved by FRET. Mol.Microbiol., Vol. 77, No. 2, pp. 384-398, 1365-2958; 0950$382 X$

Bendezu, F. O.; Hale, C. A.; Bernhardt, T. G. \& de Boer, P. A. (2009). RodZ (YfgA) is required for proper assembly of the MreB actin cytoskeleton and cell shape in E. coli. EMBO J., Vol. 28, No. 3, pp. 193-204, 1460-2075; 0261-4189

Bertsche, U.; Kast, T.; Wolf, B.; Fraipont, C.; Aarsman, M. E.; Kannenberg, K.; von Rechenberg, M.; Nguyen-Disteche, M.; den Blaauwen, T.; Holtje, J. V. \& Vollmer, W. (2006). Interaction between two murein (peptidoglycan) synthases, PBP3 and PBP1B, in Escherichia coli. Mol.Microbiol., Vol. 61, No. 3, pp. 675-690, 0950-382X; 0950-382X

Blackwood, E. M. \& Eisenman, R. N. (1995). Identification of protein-protein interactions by lambda gt11 expression cloning. Methods Enzymol., Vol. 254, pp. 229-240, 0076-6879; 0076-6879 
Borloo, J.; De Smet, L.; Vergauwen, B.; Van Beeumen, J. J. \& Devreese, B. (2007). A betagalactosidase-based bacterial two-hybrid system to assess protein-protein interactions in the correct cellular environment. J.Proteome Res., Vol. 6, No. 7, pp. 2587-2595, 1535-3893; 1535-3893

Castagnoli, L.; Vetriani, C. \& Cesareni, G. (1994). Linking an easily detectable phenotype to the folding of a common structural motif. Selection of rare turn mutations that prevent the folding of Rop. J.Mol.Biol., Vol. 237, No. 4, pp. 378-387, 0022-2836; 00222836

Chalfie, M.; Tu, Y.; Euskirchen, G.; Ward, W. W. \& Prasher, D. C. (1994). Green fluorescent protein as a marker for gene expression. Science, Vol. 263, No. 5148, pp. 802-805, 0036-8075; 0036-8075

Chudakov, D. M.; Matz, M. V.; Lukyanov, S. \& Lukyanov, K. A. (2010). Fluorescent proteins and their applications in imaging living cells and tissues. Physiol.Rev., Vol. 90, No. 3, pp. 1103-1163, 1522-1210; 0031-9333

Clegg, R. M. (1992). Fluorescence resonance energy transfer and nucleic acids. Methods Enzymol., Vol. 211, pp. 353-388, 0076-6879; 0076-6879

Clegg, R. M.; Murchie, A. I.; Zechel, A.; Carlberg, C.; Diekmann, S. \& Lilley, D. M. (1992). Fluorescence resonance energy transfer analysis of the structure of the four-way DNA junction. Biochemistry, Vol. 31, No. 20, pp. 4846-4856, 0006-2960; 0006-2960

Cody, C. W.; Prasher, D. C.; Westler, W. M.; Prendergast, F. G. \& Ward, W. W. (1993). Chemical structure of the hexapeptide chromophore of the Aequorea greenfluorescent protein. Biochemistry, Vol. 32, No. 5, pp. 1212-1218, 0006-2960; 0006-2960

Cubitt, A. B.; Heim, R.; Adams, S. R.; Boyd, A. E.; Gross, L. A. \& Tsien, R. Y. (1995). Understanding, improving and using green fluorescent proteins. Trends Biochem.Sci., Vol. 20, No. 11, pp. 448-455, 0968-0004; 0968-0004

Dautin, N.; Karimova, G.; Ullmann, A. \& Ladant, D. (2000). Sensitive genetic screen for protease activity based on a cyclic AMP signaling cascade in Escherichia coli. J.Bacteriol., Vol. 182, No. 24, pp. 7060-7066, 0021-9193; 0021-9193

Den Blaauwen, T.; Aarsman, M. E.; Vischer, N. O. \& Nanninga, N. (2003). Penicillin-binding protein PBP2 of Escherichia coli localizes preferentially in the lateral wall and at mid-cell in comparison with the old cell pole. Mol.Microbiol., Vol. 47, No. 2, pp. 539547, 0950-382X; 0950-382X

Denome, S. A.; Elf, P. K.; Henderson, T. A.; Nelson, D. E. \& Young, K. D. (1999). Escherichia coli mutants lacking all possible combinations of eight penicillin binding proteins: viability, characteristics, and implications for peptidoglycan synthesis. J.Bacteriol., Vol. 181, No. 13, pp. 3981-3993, 0021-9193; 0021-9193

Di lallo, G.; Anderluzzi, D.; Ghelardini, P. \& Paolozzi, L. (1999a). FtsZ dimerization in vivo. Mol.Microbiol., Vol. 32, No. 2, pp. 265-274, 0950-382X; 0950-382X

Di lallo, G.; Ghelardini, P. \& Paolozzi, L. (1999b). Two-hybrid assay: construction of an Escherichia coli system to quantify homodimerization ability in vivo. Microbiology, Vol. 145 ( Pt 6), No. Pt 6, pp. 1485-1490, 1350-0872; 1350-0872

Di lallo, G.; Castagnoli, L.; Ghelardini, P. \& Paolozzi, L. (2001). A two-hybrid system based on chimeric operator recognition for studying protein homo/heterodimerization in Escherichia coli. Microbiology, Vol. 147, No. Pt 6, pp. 1651-1656, 1350-0872; 1350-0872

Di lallo, G.; Fagioli, M.; Barionovi, D.; Ghelardini, P. \& Paolozzi, L. (2003). Use of a twohybrid assay to study the assembly of a complex multicomponent protein 
machinery: bacterial septosome differentiation. Microbiology, Vol. 149, No. Pt 12, pp. 3353-3359, 1350-0872; 1350-0872

Dixit, R. \& Cyr, R. (2003). Cell damage and reactive oxygen species production induced by fluorescence microscopy: effect on mitosis and guidelines for non-invasive fluorescence microscopy. Plant J., Vol. 36, No. 2, pp. 280-290, 0960-7412; 0960-7412

Dmitriev, B.; Toukach, F. \& Ehlers, S. (2005). Towards a comprehensive view of the bacterial cell wall. Trends Microbiol., Vol. 13, No. 12, pp. 569-574, 0966-842X; 0966-842X

D'Ulisse, V.; Fagioli, M.; Ghelardini, P. \& Paolozzi, L. (2007). Three functional subdomains of the Escherichia coli FtsQ protein are involved in its interaction with the other division proteins. Microbiology, Vol. 153, No. Pt 1, pp. 124-138, 1350-0872; 1350-0872

Durand-Heredia, J. M.; Yu, H. H.; De Carlo, S.; Lesser, C. F. \& Janakiraman, A. (2011). Identification and characterization of ZapC, a stabilizer of the FtsZ ring in Escherichia coli. J.Bacteriol., Vol. 193, No. 6, pp. 1405-1413, 1098-5530; 0021-9193

Fields, S. \& Song, O. (1989). A novel genetic system to detect protein-protein interactions. Nature, Vol. 340, No. 6230, pp. 245-246, 0028-0836; 0028-0836

Förster, T. (1946). Energiewanderung und Fluoreszenz. Naturwissenschaften. Vol. 6, pp. 166175

Förster, T. (1948). Zwichenmolekulare Energiewanderung und Fluoreszenz. Ann. Phys. Vol. 2, pp. 55-75,

Förster, T. (1993). Intermolecular energy migration an fluorescence, In: Biological Physics, (Mielczarek, E. V., Greenbaum, E. \& Knox, R. S., Eds.), (April 1993) American Institute of Physics, 9780883188552 New York, pp. 148-160.

Fraipont, C.; Alexeeva, S.; Wolf, B.; van der Ploeg, R.; Schloesser, M.; den Blaauwen, T. \& Nguyen-Disteche, M. (2011). The integral membrane FtsW protein and peptidoglycan synthase PBP3 form a subcomplex in Escherichia coli. Microbiology, Vol. 157, No. Pt 1, pp. 251-259, 1465-2080; 1350-0872

Fu, G.; Huang, T.; Buss, J.; Coltharp, C.; Hensel, Z. \& Xiao, J. (2010). In vivo structure of the E. coli FtsZ-ring revealed by photoactivated localization microscopy (PALM). PLoS One, Vol. 5, No. 9, pp. e12682, 1932-6203; 1932-6203

Gadella, T. W. J. (2008). FRET and FLIM techniques, In: Laboratory techniques in biochemistry and molecular biology, (Pillai S. \& van der Vliet, P. C., Eds.), (Dec 2008), Elsevier, 9780080549583, Amsterdam, The Netherlands

Gan, L.; Chen, S. \& Jensen, G. J. (2008). Molecular organization of Gram-negative peptidoglycan. Proc.Natl.Acad.Sci.U.S.A., Vol. 105, No. 48, pp. 18953-18957, 10916490; 0027-8424

Griesbeck, O.; Baird, G. S.; Campbell, R. E.; Zacharias, D. A. \& Tsien, R. Y. (2001). Reducing the environmental sensitivity of yellow fluorescent protein. Mechanism and applications. J.Biol.Chem., Vol. 276, No. 31, pp. 29188-29194, 0021-9258; 0021-9258

Hale, C. A. \& de Boer, P. A. (1999). Recruitment of ZipA to the septal ring of Escherichia coli is dependent on FtsZ and independent of FtsA. J.Bacteriol., Vol. 181, No. 1, pp. 167176, 0021-9193; 0021-9193

Hale, C. A.; Shiomi, D.; Liu, B.; Bernhardt, T. G.; Margolin, W.; Niki, H. \& de Boer, P. A. (2011). Identification of Escherichia coli ZapC (YcbW) as a component of the division apparatus that binds and bundles FtsZ polymers. J.Bacteriol., Vol. 193, No. 6, pp. 1393-1404, 1098-5530; 0021-9193 
Hayhurst, E. J.; Kailas, L.; Hobbs, J. K. \& Foster, S. J. (2008). Cell wall peptidoglycan architecture in Bacillus subtilis. Proc.Natl.Acad.Sci.U.S.A., Vol. 105, No. 38, pp. 1460314608, 1091-6490; 0027-8424

Hu, J. C.; O'Shea, E. K.; Kim, P. S. \& Sauer, R. T. (1990). Sequence requirements for coiledcoils: analysis with lambda repressor-GCN4 leucine zipper fusions. Science, Vol. 250, No. 4986, pp. 1400-1403, 0036-8075; 0036-8075

Jacobson, R. H.; Zhang, X. J.; DuBose, R. F. \& Matthews, B. W. (1994). Three-dimensional structure of beta-galactosidase from E. coli. Nature, Vol. 369, No. 6483, pp. 761-766, 0028-0836; 0028-0836

Joung, J. K.; Ramm, E. I. \& Pabo, C. O. (2000). A bacterial two-hybrid selection system for studying protein-DNA and protein-protein interactions. Proc.Natl.Acad.Sci.U.S.A., Vol. 97, No. 13, pp. 7382-7387, 0027-8424; 0027-8424

Kain, S. R.; Adams, M.; Kondepudi, A.; Yang, T. T.; Ward, W. W. \& Kitts, P. (1995). Green fluorescent protein as a reporter of gene expression and protein localization. BioTechniques, Vol. 19, No. 4, pp. 650-655, 0736-6205; 0736-6205

Karasawa, S.; Araki, T.; Nagai, T.; Mizuno, H. \& Miyawaki, A. (2004). Cyan-emitting and orange-emitting fluorescent proteins as a donor/acceptor pair for fluorescence resonance energy transfer. Biochem.J., Vol. 381, No. Pt 1, pp. 307-312, 1470-8728; 0264-6021

Karimova, G.; Pidoux, J.; Ullmann, A. \& Ladant, D. (1998). A bacterial two-hybrid system based on a reconstituted signal transduction pathway. Proc.Natl.Acad.Sci.U.S.A., Vol. 95, No. 10, pp. 5752-5756, 0027-8424; 0027-8424

Karimova, G.; Dautin, N. \& Ladant, D. (2005). Interaction network among Escherichia coli membrane proteins involved in cell division as revealed by bacterial two-hybrid analysis. J.Bacteriol., Vol. 187, No. 7, pp. 2233-2243, 0021-9193; 0021-9193

Koch, A. L. \& Woeste, S. (1992). Elasticity of the sacculus of Escherichia coli. J.Bacteriol., Vol. 174, No. 14, pp. 4811-4819, 0021-9193; 0021-9193

Kremers, G. J.; Goedhart, J.; van Munster, E. B. \& Gadella, T. W.,Jr. (2006). Cyan and yellow super fluorescent proteins with improved brightness, protein folding, and FRET Forster radius. Biochemistry, Vol. 45, No. 21, pp. 6570-6580, 0006-2960; 0006-2960

Ladant, D. (1988). Interaction of Bordetella pertussis adenylate cyclase with calmodulin. Identification of two separated calmodulin-binding domains. J.Biol.Chem., Vol. 263, No. 6, pp. 2612-2618, 0021-9258; 0021-9258

Ladant, D. \& Karimova, G. (2000). Genetic systems for analyzing protein-protein interactions in bacteria. Res.Microbiol., Vol. 151, No. 9, pp. 711-720, 0923-2508; 09232508

Lakowicz, J. R. (2006). Principles of fluorescence spectroscopy (3), Springer, 038731278-1, New York, United States of America

Longo, F.; Marchetti, M. A.; Castagnoli, L.; Battaglia, P. A. \& Gigliani, F. (1995). A novel approach to protein-protein interaction: complex formation between the p53 tumor suppressor and the HIV Tat proteins. Biochem.Biophys.Res.Commun., Vol. 206, No. 1, pp. 326-334, 0006-291X; 0006-291X

Maggi, S.; Massidda, O.; Luzi, G.; Fadda, D.; Paolozzi, L. \& Ghelardini, P. (2008). Division protein interaction web: identification of a phylogenetically conserved common interactome between Streptococcus pneumoniae and Escherichia coli. Microbiology, Vol. 154, No. Pt 10, pp. 3042-3052, 1350-0872; 1350-0872 
Miller, J. H. (1972). Experiments in molecular genetics (), Cold Spring Harbor Laboratory Press, 0879691069, New York, United States of America

Murchie, A. I.; Clegg, R. M.; von Kitzing, E.; Duckett, D. R.; Diekmann, S. \& Lilley, D. M. (1989). Fluorescence energy transfer shows that the four-way DNA junction is a right-handed cross of antiparallel molecules. Nature, Vol. 341, No. 6244, pp. 763766, 0028-0836; 0028-0836

Ormo, M.; Cubitt, A. B.; Kallio, K.; Gross, L. A.; Tsien, R. Y. \& Remington, S. J. (1996). Crystal structure of the Aequorea victoria green fluorescent protein. Science, Vol. 273, No. 5280, pp. 1392-1395, 0036-8075; 0036-8075

Perozzo, M. A.; Ward, K. B.; Thompson, R. B. \& Ward, W. W. (1988). X-ray diffraction and time-resolved fluorescence analyses of Aequorea green fluorescent protein crystals. J.Biol.Chem., Vol. 263, No. 16, pp. 7713-7716, 0021-9258; 0021-9258

Potluri, L.; Karczmarek, A.; Verheul, J.; Piette, A.; Wilkin, J. M.; Werth, N.; Banzhaf, M.; Vollmer, W.; Young, K. D.; Nguyen-Disteche, M. \& den Blaauwen, T. (2010). Septal and lateral wall localization of PBP5, the major D,D-carboxypeptidase of Escherichia coli, requires substrate recognition and membrane attachment. Mol.Microbiol., Vol. 77, No. 2, pp.300-323, 1365-2958; 0950-382X

Prasher, D. C.; Eckenrode, V. K.; Ward, W. W.; Prendergast, F. G. \& Cormier, M. J. (1992). Primary structure of the Aequorea victoria green-fluorescent protein. Gene, Vol. 111, No. 2, pp. 229-233, 0378-1119; 0378-1119

Rossi, F.; Charlton, C. A. \& Blau, H. M. (1997). Monitoring protein-protein interactions in intact eukaryotic cells by beta-galactosidase complementation. Proc.Natl. Acad.Sci.U.S.A., Vol. 94, No. 16, pp. 8405-8410, 0027-8424; 0027-8424

Sauvage, E.; Kerff, F.; Terrak, M.; Ayala, J. A. \& Charlier, P. (2008). The penicillin-binding proteins: structure and role in peptidoglycan biosynthesis. FEMS Microbiol.Rev., Vol. 32, No. 2, pp. 234-258, 0168-6445; 0168-6445

Shaner, N. C.; Campbell, R. E.; Steinbach, P. A.; Giepmans, B. N.; Palmer, A. E. \& Tsien, R. Y. (2004). Improved monomeric red, orange and yellow fluorescent proteins derived from Discosoma sp. red fluorescent protein. Nat.Biotechnol., Vol. 22, No. 12, pp. 15671572, 1087-0156; 1087-0156

Shaner, N. C.; Lin, M. Z.; McKeown, M. R.; Steinbach, P. A.; Hazelwood, K. L.; Davidson, M. W. \& Tsien, R. Y. (2008). Improving the photostability of bright monomeric orange and red fluorescent proteins. Nat.Methods, Vol. 5, No. 6, pp. 545-551, 1548-7105; 1548-7091

Shimomura, O. (1979). Structure of the chromophore of Aequorea green fluorescent protein . FEBS Lett, Vol. 104, No. 2, pp. 220-222,

Sourjik, V. \& Berg, H. C. (2002). Receptor sensitivity in bacterial chemotaxis. Proc.Natl.Acad.Sci.U.S.A., Vol. 99, No. 1, pp.123-127, 0027-8424; 0027-8424

Sourjik, V. \& Berg, H. C. (2004). Functional interactions between receptors in bacterial chemotaxis. Nature, Vol. 428, No. 6981, pp. 437-441, 1476-4687; 0028-0836

Sourjik, V.; Vaknin, A.; Shimizu, T. S. \& Berg, H. C. (2007). In vivo measurement by FRET of pathway activity in bacterial chemotaxis. Methods Enzymol., Vol. 423, pp. 365-391, 0076-6879; 0076-6879

Strauch, E. M. \& Georgiou, G. (2007). A bacterial two-hybrid system based on the twinarginine transporter pathway of E. coli. Protein Sci., Vol. 16, No. 5, pp. 1001-1008, 0961-8368; 0961-8368 
Thaler, C.; Vogel, S. S.; Ikeda, S. R. \& Chen, H. (2006). Photobleaching of YFP does not produce a CFP-like species that affects FRET measurements. Nat.Methods, Vol. 3, No. 7, pp. 491; author reply 492-3, 1548-7091; 1548-7091

Ullmann, A.; Jacob, F. \& Monod, J. (1967). Characterization by in vitro complementation of a peptide corresponding to an operator-proximal segment of the beta-galactosidase structural gene of Escherichia coli. J.Mol.Biol., Vol. 24, No. 2, pp. 339-343, 0022-2836; 0022-2836

Valentin, G.; Verheggen, C.; Piolot, T.; Neel, H.; Coppey-Moisan, M. \& Bertrand, E. (2005). Photoconversion of YFP into a CFP-like species during acceptor photobleaching FRET experiments. Nat.Methods, Vol. 2, No. 11, pp. 801, 1548-7091; 1548-7091

Vidal, M. \& Legrain, P. (1999). Yeast forward and reverse 'n'-hybrid systems. Nucleic Acids Res., Vol. 27, No. 4, pp. 919-929, 0305-1048; 0305-1048

Vladimirov, N. \& Sourjik, V. (2009). Chemotaxis: how bacteria use memory. Biol.Chem., Vol. 390, No. 11, pp. 1097-1104, 1437-4315; 1431-6730

Vollmer, W. \& Bertsche, U. (2008). Murein (peptidoglycan) structure, architecture and biosynthesis in Escherichia coli. Biochim.Biophys.Acta, Vol. 1778, No. 9, pp. 1714-1734, 0006-3002; 0006-3002

Vollmer, W.; Blanot, D. \& de Pedro, M. A. (2008). Peptidoglycan structure and architecture. FEMS Microbiol.Rev., Vol. 32, No. 2, pp. 149-167, 0168-6445; 0168-6445

Vollmer, W. \& Seligman, S. J. (2010). Architecture of peptidoglycan: more data and more models. Trends Microbiol., Vol. 18, No. 2, pp. 59-66, 1878-4380; 0966-842X

Volz, K. \& Matsumura, P. (1991). Crystal structure of Escherichia coli CheY refined at 1.7-A resolution. J.Biol.Chem., Vol. 266, No. 23, pp.15511-15519, 0021-9258; 0021-9258

Wehrman, T.; Kleaveland, B.; Her, J. H.; Balint, R. F. \& Blau, H. M. (2002). Protein-protein interactions monitored in mammalian cells via complementation of beta -lactamase enzyme fragments. Proc.Natl.Acad.Sci.U.S.A., Vol. 99, No. 6, pp. 3469-3474, 00278424; 0027-8424

Weiss, D. S.; Pogliano, K.; Carson, M.; Guzman, L. M.; Fraipont, C.; Nguyen-Disteche, M.; Losick, R. \& Beckwith, J. (1997). Localization of the Escherichia coli cell division protein Ftsl (PBP3) to the division site and cell pole. Mol.Microbiol., Vol. 25, No. 4, pp. 671-681, 0950-382X; 0950-382X

Weiss, D. S.; Chen, J. C.; Ghigo, J. M.; Boyd, D. \& Beckwith, J. (1999). Localization of FtsI (PBP3) to the septal ring requires its membrane anchor, the $\mathrm{Z}$ ring, FtsA, FtsQ, and FtsL. J.Bacteriol., Vol. 181, No. 2, pp. 508-520, 0021-9193; 0021-9193

Willemse, J.; Borst, J. W.; de Waal, E.; Bisseling, T. \& van Wezel, G. P. (2011). Positive control of cell division: FtsZ is recruited by $\mathrm{SsgB}$ during sporulation of Streptomyces. Genes Dev., Vol. 25, No. 1, pp. 89-99, 1549-5477; 0890-9369

Wlodarczyk, J.; Woehler, A.; Kobe, F.; Ponimaskin, E.; Zeug, A. \& Neher, E. (2008). Analysis of FRET signals in the presence of free donors and acceptors. Biophys.J., Vol. 94, No. 3, pp. 986-1000, 1542-0086; 0006-3495

Wolfe, S. A.; Greisman, H. A.; Ramm, E. I. \& Pabo, C. O. (1999). Analysis of zinc fingers optimized via phage display: evaluating the utility of a recognition code. J.Mol.Biol., Vol. 285, No. 5, pp. 1917-1934, 0022-2836; 0022-2836

Zhao, R.; Collins, E. J.; Bourret, R. B. \& Silversmith, R. E. (2002). Structure and catalytic mechanism of the E. coli chemotaxis phosphatase CheZ. Nat.Struct.Biol., Vol. 9, No. 8, pp. $570-575,1072-8368 ; 1072-8368$ 


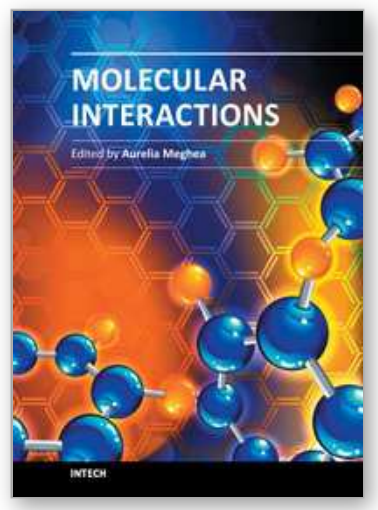

\author{
Molecular Interactions \\ Edited by Prof. Aurelia Meghea
}

ISBN 978-953-51-0079-9

Hard cover, 400 pages

Publisher InTech

Published online 29, February, 2012

Published in print edition February, 2012

In a classical approach materials science is mainly dealing with interatomic interactions within molecules, without paying much interest on weak intermolecular interactions. However, the variety of structures actually is the result of weak ordering because of noncovalent interactions. Indeed, for self-assembly to be possible in soft materials, it is evident that forces between molecules must be much weaker than covalent bonds between the atoms of a molecule. The weak intermolecular interactions responsible for molecular ordering in soft materials include hydrogen bonds, coordination bonds in ligands and complexes, ionic and dipolar interactions, van der Waals forces, and hydrophobic interactions. Recent evolutions in nanosciences and nanotechnologies provide strong arguments to support the opportunity and importance of the topics approached in this book, the fundamental and applicative aspects related to molecular interactions being of large interest in both research and innovative environments. We expect this book to have a strong impact at various education and research training levels, for young and experienced researchers from both academia and industry.

\title{
How to reference
}

In order to correctly reference this scholarly work, feel free to copy and paste the following:

René van der Ploeg and Tanneke den Blaauwen (2012). In Vivo Bacterial Morphogenetic Protein Interactions, Molecular Interactions, Prof. Aurelia Meghea (Ed.), ISBN: 978-953-51-0079-9, InTech, Available from: http://www.intechopen.com/books/molecular-interactions/in-vivo-bacterial-morphogenetic-protein-interactions

\section{INTECH}

open science | open minds

\section{InTech Europe}

University Campus STeP Ri

Slavka Krautzeka 83/A

51000 Rijeka, Croatia

Phone: +385 (51) 770447

Fax: +385 (51) 686166

www.intechopen.com

\section{InTech China}

Unit 405, Office Block, Hotel Equatorial Shanghai No.65, Yan An Road (West), Shanghai, 200040, China 中国上海市延安西路65号上海国际贵都大饭店办公楼405单元 Phone: +86-21-62489820

Fax: +86-21-62489821 
(C) 2012 The Author(s). Licensee IntechOpen. This is an open access article distributed under the terms of the Creative Commons Attribution 3.0 License, which permits unrestricted use, distribution, and reproduction in any medium, provided the original work is properly cited. 